RR-75-1

TRANSIENT FLOW ROUTING IN CHANNEL NETWORKS

Eric F. Wood

Brendan M. Harley

Frank G. Perkins

January 1975

Research Reports are publications reporting on the work of the author. Any views or conclusions are those of the author, and do not necessarily reflect those of IIASA. 


\section{Transient Flow Routing in Channel Networks}

Eric F. Wood ${ }^{1}$, Brendan M. Harley ${ }^{2}$ and Frank G. Perkins 3,4

\section{$\underline{\text { Abstract }}$}

The formulation of a mathematical model to predict transient flows in hydraulic networks is presented. The network formulation consists of breaking the network into a series of connected reaches; reducing the finite difference equations for each reach into two "reach" equations; forming an exterior matrix consisting of the reach equations, external boundary conditions, and interior compatibility conditions; solving the external matrix for the end values of discharge and water surface elevation for all reaches and back-substituting for all interior values. Examples presented include the James River, USA, estuary model (twentyfour nodes and twenty-six reaches), the Cork Harbour, Ireland, estuary (thirteen-reach, double-looped network), and the Rio Bayamon basin, Puerto Rico. Results are very satisfactory when compared to known data.

IInternational Institute for Applied systems Analysis, Schloss Laxenburg, A-2361 Laxenburg, Austria.

${ }^{2}$ Resource Analysis, Incorporated, 1033 Massachusetts Ave., Cambridge, Massachusetts 02138.

${ }^{3}$ Department of Civil Engineering, Massachusetts Institute of Engineering, Cambridge, Massachusetts 02139.

4 The authors are grateful to Prof. James Dailey, Dept. of Civil Engineering, University of Texas, Austin, and Prof. D. Harleman, Dept. of Civil Engineering, M.I.T., Cambridge, Massachusetts, for their contributions in applying the model to some realistic case studies. The authors are also grateful to Dr. D. Gunaratnam for his initial work on the problem. The development of the model was supported by the Office of Water Resource Research, U.S. Dept. of the Interior, under Grants 14-31-0001-3159, 14-01-0001-1988, and 14-31-0001-3716. Finally, the authors would like to thank John C. Schaake, Jr., currently with the U.S. Weather Bureau, NOAA, whose contributions and suggestions during the Rio Bayamon study helped make this flood routing model a reliable engineering tool, and express their appreciation to the Departments of Public Works and Natural Resources of the Commonwealth of Puerto Rico for their cooperation. 
Introduction

Routing procedures, based upon the unsteady flow equations for continuity and momentum, have been used for many years to solve for transient flows in open channels. Both implicit and explicit solution techniques for the governing equations have been widely reported in the literature (Stocker [6]; Gunaratnam (3]). The practical application of transient flow routing schemes for large river systems has been severely limited by the inability to adequately handle complex channel networks. Recently reported multichannel formulations (Quinn and Wylie [5]; Fread [2]) have considered only a main river with a single tributary--the simple $Y$ network. The solution for the stage and the discharge at the internal junction is obtained by a Newton-Raphson algorithm. The Newton-Raphson approach has two main disadvantages, which severely limits its usefulness in engineering analysis on large, complex networks. These disadvantages are:

1) The formation of a large matrix of partial derivatives, and

2) The repetitious solution of the matrix of partial derivations as the algorithm iterates to the new solution for the stage and discharges.

The procedure of matrix formulation and solution must iterate to the new solution at each time step--an approach that is expensive and cumbersome for large networks without assuring that a satisfactory solution will be achieved.

Incorporating a practical solution technique for the unsteady flow network routing problem involves the following considerations:

1) Specifying a set of external boundary conditions,

2) Solving for the set of simultaneous algebraic difference equations arising trom the finite difference equations of continuity and momentum,

3) Satisfying the internal boundary condition of stage and discharge compatibility,

4) Specifying, for implicit finite difference schemes, the initial stage and discharge conditions. For transient flow simulation in rivers, the required initial conditions of stages and discharges are generally not specifically available. The capability to generate the initial conditions is of practical importance. Conditions under which initial stages and discharges can be obtained are discussed later. 
The network formulation presented here is generally applicable to finite difference schemes. In this paper, both a six-point implicit scheme and a simpler four-point implicit scheme were used in the solutions of the examples presented. The network formulation is the same for both; the six-point scheme will be presented in detail.

\section{Single-Reach General Boundary Conditions}

Consider a channel divided into (N-1) sections. In the formulation of the implicit scheme there is a total of $(2 \mathrm{~N}-2)$ unknowns; $2 \mathrm{~N}-4$ of these are unknown values of discharge, $Q$, and water surface elevation, $\mathrm{Z}$, at the interior points, while one unknown is provided by each of the boundary conditions, leaving one unknown at each boundary point.

The St. Venant equations that govern unsteady flow are often written in a characteristic form. They can then be solved by a suitable finite difference procedure. One such procedure, developed by Gunaratnam and Perkins [3], uses a six-point scheme that resulted in the following finite difference equation for the characteristic equations for the interior points:

$$
\begin{aligned}
& \left(\frac{1}{6}-\frac{\Delta t}{\Delta x} \frac{\lambda}{2}\right) z_{j-1}^{n+1}+\left(\frac{2}{3}\right) z_{j}^{n+1}+\left(\frac{1}{6}+\frac{\Delta t}{\Delta x} \frac{\lambda}{2}\right) z_{j+1}^{n+1} \\
& -\frac{1}{B_{0} \lambda^{\star}}\left(\frac{1}{6}-\frac{\Delta t}{\Delta x} \frac{\lambda}{2}\right) q_{j-1}^{n+1} \\
& -\frac{1}{B_{0} \lambda^{\star}}\left(\frac{2}{3}\right) q_{j}^{n+1}-\frac{1}{B_{0}^{\lambda^{\star}}}\left(\frac{1}{6}+\frac{\Delta t}{\Delta x} \frac{\lambda}{2}\right) q_{j+1}^{n+1} \\
& -\frac{\Delta t \psi}{}+\left(\frac{1}{6} z_{j-1}^{n}+\frac{2}{3} z_{j}^{n}+\frac{1}{6} z_{j+1}^{n}\right) \\
& -\frac{1}{B_{0} \lambda^{\star}}\left(\frac{1}{6} q_{j-1}^{n}+\frac{2}{3} q_{j}^{n}+\frac{1}{6} q_{j+1}^{n}\right), \\
& j=2, \ldots, N-1,
\end{aligned}
$$

where

$$
\begin{aligned}
& \Delta t \text { is the time step } \\
& \Delta x \text { is the space step } \\
& z_{j}^{n} \text { is the water surface elevation at section } j, \\
& \text { time step } n
\end{aligned}
$$


$q_{j}^{n}$ is the discharge at section $j$, time step $n$

$B_{0}$ is the top width of the channel

$\psi=-\frac{A g}{B_{O} \lambda^{\ddagger}}\left[\left(\left.\frac{\partial A}{\partial x}\right|_{z=\text { const. }} \frac{F^{2}}{B_{O}}\right)-S_{f}\right]-\frac{q_{L}}{B_{O}}$

$A$ is the cross-sectional area

$F$ is the Froude number

$\mathrm{g}$ is the gravitational constant

$S_{f}$ is the friction slope

$\mathrm{q}_{\mathrm{L}}$ is the lateral inflow.

Equation (la) generates two finite difference equations. One is for the forward characteristic, when

$$
\begin{aligned}
& \dot{\lambda}=v+c \\
& \lambda^{*}=v-c,
\end{aligned}
$$

and the other is for the backward characteristic, when

$$
\begin{aligned}
& \lambda=v-c \\
& \lambda^{*}=v+c
\end{aligned}
$$

where

$$
\begin{aligned}
& \mathrm{v}=\text { the velocity } \\
& \mathrm{c}=\text { the celerity velocity }
\end{aligned}
$$

For the solution of the finite difference equations to exist and to be unique, it is necessary to specify both the boundary and initial conditions. In the case of subcritical flow, the boundary conditions take the form of known time histories of either the water surface elevation $\mathrm{Z}$ or the discharge $Q$, or a relationship between $Q$ and $Z$. These time histories must be specified continuously over the time interval for which the transient is to be observed. Since the present formulation is limited to subcritical flows, only one time history is required at each boundary. At an upstream boundary, only the backward characteristic equation governs; at a downstream boundary, the forward characteristic equation governs as shown in Figure 1 . Therefore, for the upstream boundary, 


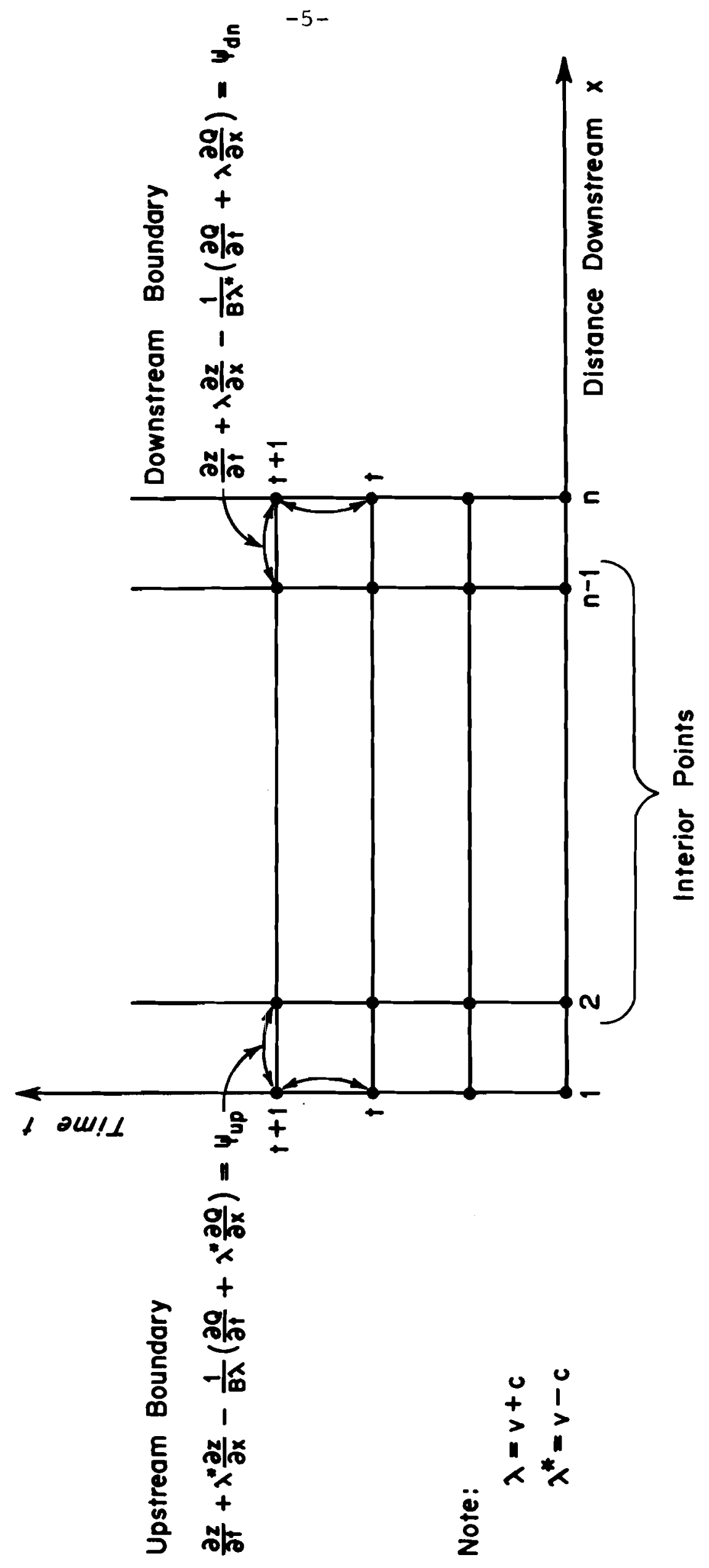

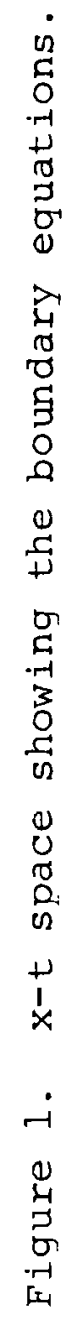




$$
\begin{aligned}
& \lambda=\lambda_{\text {up }}=(v-c) \\
& \lambda *=\lambda_{\text {up }}^{*}=(v+c),
\end{aligned}
$$

and for the downstream boundary

$$
\begin{aligned}
& \lambda=\lambda_{\mathrm{dn}}=(\mathrm{v}+\mathrm{c}) \\
& \lambda^{*}=\lambda_{\mathrm{dn}}^{*}=(\mathrm{v}-\mathrm{c}) .
\end{aligned}
$$

Hence the equations for the upstream and downstream boundary points are given below:

$$
\begin{aligned}
\left(\frac{1}{3}\right. & \left.-\frac{\Delta t}{\Delta x} \frac{\lambda u p}{2}\right) z_{1}^{n+1}+\left(\frac{1}{6}+\frac{\Delta t}{\Delta x} \frac{\lambda u p}{2}\right) z_{2}^{n+1} \\
& -\frac{1}{B_{0}{ }^{\lambda^{\star}} \text { up }}\left(\frac{1}{3}-\frac{\Delta t}{\Delta x} \frac{\lambda u p}{2}\right) q_{1}^{n+1}-\frac{1}{B_{0}^{\lambda^{\star}} u p}\left(\frac{1}{6}+\frac{\Delta t}{\Delta x} \frac{\lambda u p}{2}\right) q_{2}^{n+1} \\
& =\psi_{u p}+\left(\frac{1}{3} z_{1}^{n}+\frac{1}{6} z_{1}^{n}\right)-\frac{1}{B_{0}{ }^{\lambda^{\star}} u p}\left(\frac{1}{3} q_{1}^{n}+\frac{1}{6} q_{2}^{n}\right), \quad(1 b)
\end{aligned}
$$

and

$$
\begin{aligned}
\left(\frac{1}{6}\right. & \left.-\frac{\Delta t}{\Delta x} \frac{\lambda d n}{2}\right) z_{N-1}^{n+1}+\left(\frac{1}{3}+\frac{\Delta t}{\Delta x} \frac{\lambda d n}{2}\right) z_{N}^{n+1} \\
& -\frac{1}{B_{0} \lambda^{\star}}\left(\frac{1}{6}-\frac{\Delta t}{\Delta x} \frac{\lambda d n}{2}\right) q_{N-1}^{n+1}-\frac{1}{B_{0} \lambda_{d n}^{\star}}\left(\frac{1}{3}+\frac{\Delta t}{\Delta x} \frac{\lambda d n}{2}\right) g_{N}^{n+1} \\
& =\psi_{d n}+\left(\frac{1}{6} z_{N-1}^{n}+\frac{1}{3} z_{N}^{n}\right)-\frac{1}{B_{0}^{\lambda^{\star}} d n}\left(\frac{1}{6} q_{N-1}^{n}+\frac{1}{3} q_{N}^{n}\right)
\end{aligned}
$$

Equations (la), (1b), and (lc) resulted in the set of finite difference equations for the flood routing model.

The sets of characteristic equations given in the formulation of the implicit scheme can be written for the interior and boundary points; coefficients of the matrix thus formed are displayed in Figure 2. A convenient way of solving for the variables can be developed by partitioning the matrix so that the interior points are isolated from the boundary points. The coefficients of the interior points form a $(2 \mathrm{~N}-4)$ by $(2 \mathrm{~N}-4)$ matrix which will be represented as A. The method of solution is then similar to the method of influence functions commonly used in structural analysis. In this method the vector of unknown interior points, $x$, is initially solved for with the boundary points set equal to zero. 


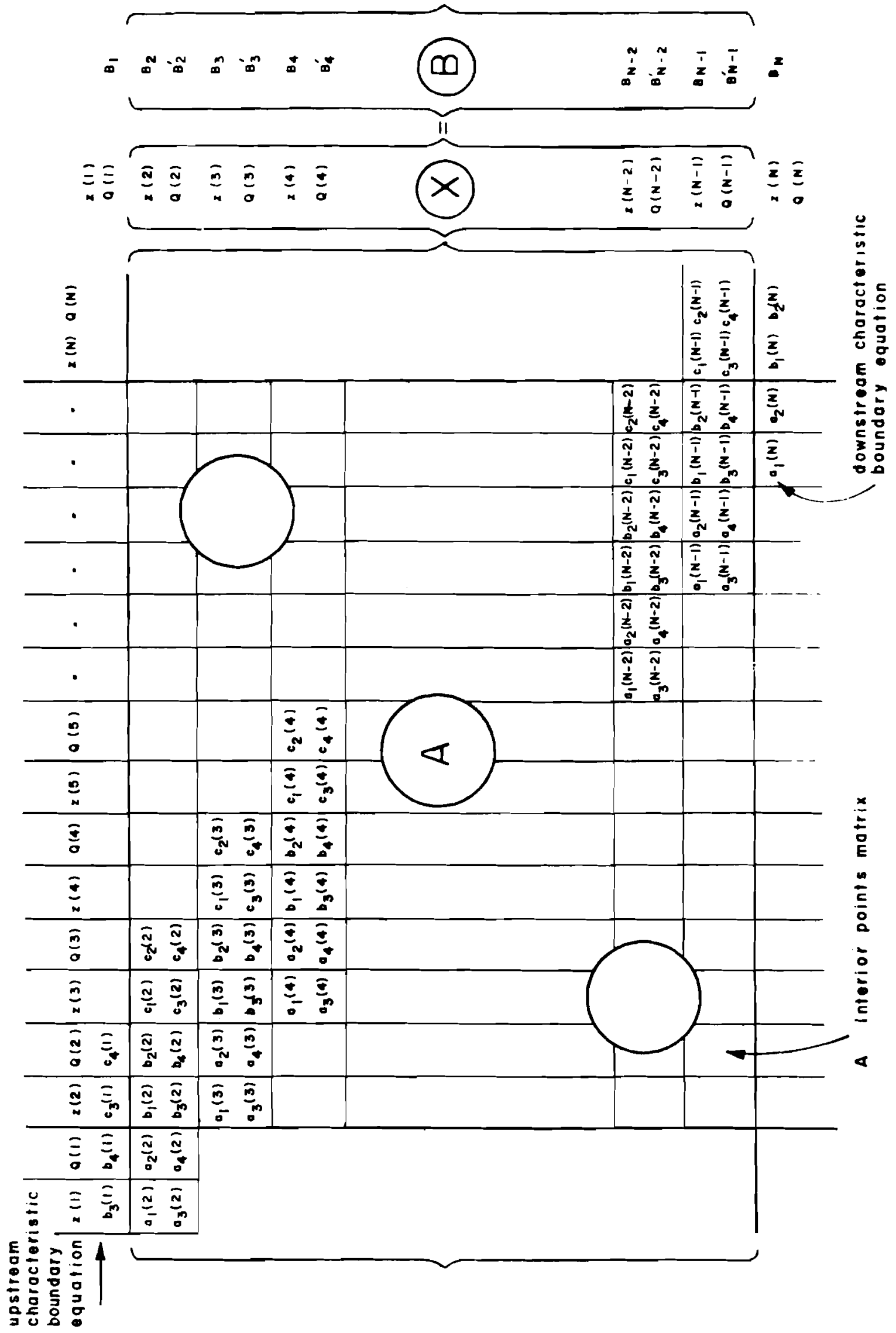


Hence

$$
\begin{aligned}
& \text { A } x^{\circ}=B \\
& x^{0}=A^{-1} B \\
& =A^{-1} \operatorname{where}^{0}=\left[\begin{array}{c}
z^{\circ}(2) \\
Q^{\circ}(2) \\
z^{\circ}(3) \\
Q^{\circ}(3) \\
- \\
- \\
- \\
- \\
z^{\circ}(N-1) \\
Q^{\circ}(N-1)
\end{array}\right]
\end{aligned}
$$

The effect of the boundary points is determined by the influence of unit values of $Z(1), Q(1), Z(N)$, and $Q(N)$. The effect of the unit influence coefficients can be found by the equation below:

$$
\begin{array}{rlr}
A \delta x_{i} & =\delta B_{i}, & i=1,2,3,4, \\
\delta x_{i} & =A^{-1} \delta B_{1}, &
\end{array}
$$

where

$$
\delta B_{1}=\left[\begin{array}{c}
-a_{1}(2) \\
-a_{3}(2) \\
0 \\
- \\
- \\
- \\
- \\
0
\end{array}\right] \quad \delta B_{2}=\left[\begin{array}{l}
-a_{2}(2) \\
-a_{4}(2) \\
0 \\
- \\
- \\
- \\
-
\end{array}\right]
$$




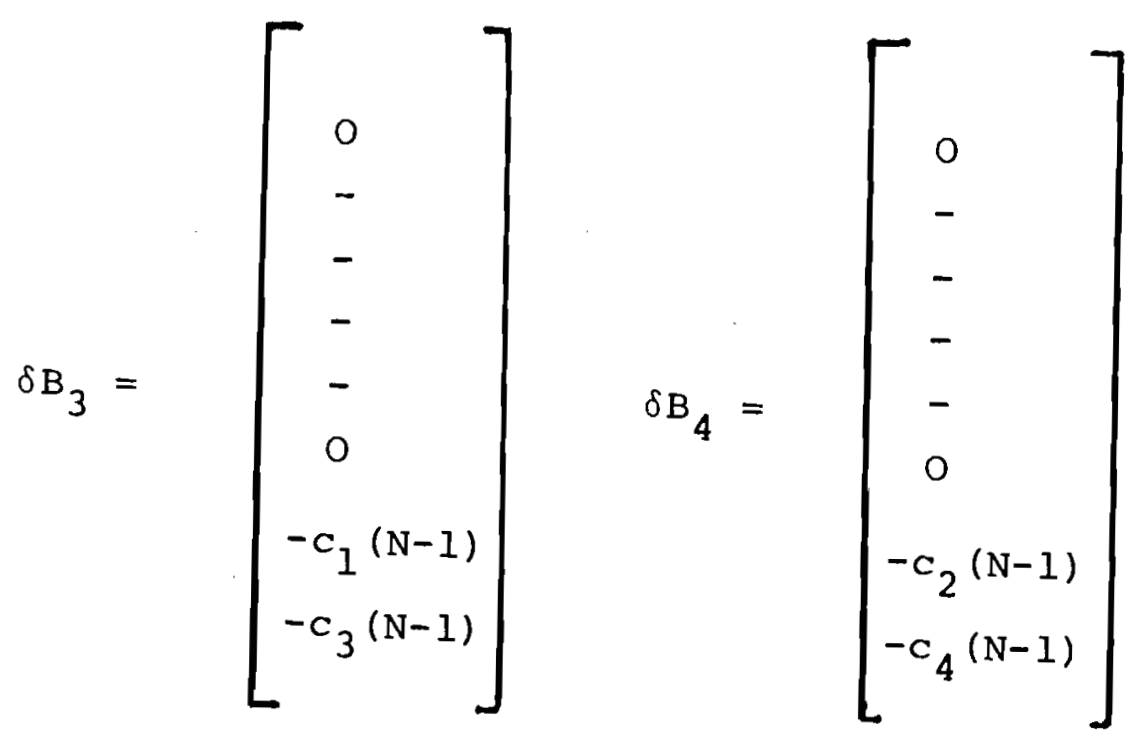

and

$$
\begin{aligned}
& \delta x_{1}=\left[\begin{array}{c}
d x_{1}(2) \\
d x_{2}(2) \\
d x_{1}(3) \\
d x_{2}(3) \\
- \\
- \\
- \\
- \\
d x_{1}(N-1) \\
d x_{2}(N-1)
\end{array}\right] \delta x_{2}=\left[\begin{array}{l}
d x_{3}(2) \\
d x_{4}(2) \\
d x_{3}(3) \\
d x_{4}(3) \\
- \\
- \\
- \\
- \\
d x_{3}(N-1) \\
d x_{4}(N-1)
\end{array}\right] \\
& \delta x_{3}=\left[\begin{array}{c}
d x_{11}(2) \\
d x_{22}(2) \\
- \\
- \\
- \\
- \\
d x_{11}(N-1) \\
d x_{22}(N-1)
\end{array}\right] \quad \delta x_{4}=\left[\begin{array}{c}
d x_{33}(2) \\
d x_{44}(2) \\
- \\
- \\
- \\
- \\
d x_{33}(N-1) \\
d x_{44}^{(N-1)}
\end{array}\right]
\end{aligned}
$$


where the terms $a_{i}(j), b_{i}(j)$, and $c_{i}(j)$ are as defined in Figure 2 .

From these equations, the value of discharge $Q(j)$ and water surface elevation $Z(j)$ for interior points can be determined in terms of their initial values (at the previous time step) and boundary point values, as follows:

$$
\begin{aligned}
Z(j)=Z^{O}(j) & +d x_{1}(j) \cdot Z(1)+d x_{3}(j) \cdot Q(1) \\
& +d x_{11}(j) \cdot z(N)+d x_{33}(j) \cdot Q(N) ; \\
Q(j)=Q^{O}(j) & +d x_{2}(j) \cdot z_{1}+d x_{4}(j) \cdot Q(1) \\
& +d x_{22}(j) \cdot Z(N)+d x_{44}(j) \cdot Q(N)
\end{aligned}
$$

It can be further seen by examination of Figure 1 that the boundary equations can be written in terms of only the boundary variables, i.e.,

$$
\alpha_{1} z(1)+\alpha_{2} Q(1)+\alpha_{3} z(N)+\alpha_{4} Q(N)=B_{1}^{\prime}
$$

for the upstream boundary, and

$$
B_{1} z(1)+B_{2} Q(1)+B_{3} z(N)+B_{4} Q(N)=B_{N}^{\prime}
$$

for the downstream boundary,

where

$$
\begin{aligned}
& \alpha_{1}=b_{3}(1)+d x_{1}(2) c_{3}(1)+d x_{2}(2) c_{4}(1) \\
& \alpha_{2}=b_{4}(1)+d x_{3}(2) c_{3}(1)+d x_{4}(2) c_{4}(1) \\
& \alpha_{3}=d x_{11}(2) c_{3}(1)+d x_{22}(2) c_{4}(1) \\
& \alpha_{4}=d x_{33}(2) c_{3}(1)+d x_{44}(2) c_{4}(1)
\end{aligned}
$$




$$
\begin{aligned}
& B_{1}=d x_{1}(N-1) a_{1}(N)+d x_{2}(N-1) a_{2}(N) \\
& B_{2}=d x_{3}(N-1) a_{1}(N)+d x_{4}(N-1) a_{2}(N) \\
& B_{3}=b_{1}(N)+d x_{11}(N-1) a_{1}(N)+d x_{22}(N-1) a_{2}(N) \\
& B_{4}=b_{2}(N)+d x_{33}(N-1) a_{1}(N)+d x_{44}(N-1) a_{2}(N) \\
& B_{1}^{\prime}=B_{1}-c_{3}(1) z^{\circ}(2)-c_{4}(1) Q^{\circ}(2) \\
& B_{N}^{\prime}=B_{N}-a_{1}(N) z^{\circ}(N-1)-a_{2}(N) Q^{\circ}(N-1) .
\end{aligned}
$$

In all cases at the boundaries either $\mathrm{Z}(1)$ or $\mathrm{Q}(1)$ and either $\mathrm{Z}(\mathrm{N})$ or $\mathrm{Q}(\mathrm{N})$ are known. Hence in Equations (5) and (6) there are two unknowns and two equations, and all the boundary values can be determined. The values for the interior points can be determined by back-substitution into Equations (4a) and (4b).

While this procedure may at first appear to be quite complex and more complicated than would be required to solve the implicit equations directly, it in fact offers a distinct computation advantage. The operations defined by Equations (2) and (3) are quite readily carried out because of the bi-tridiagonal nature of the interior matrix $A$. The details of the solution procedure are given in Gunaratnam and Perkins [3], where it is shown that the number of computations required is linearly related to the size of the matrix $A$, rather than its cube as in direct reduction techniques. Hence the five solutions implied by Equations (2) and (3) can actually be effected more rapidly than by a single direct reduction. This advantage could, of course, have been realized directly without treating the boundary and interior points separately. However, by doing so, very major advantages are realized when dealing with a network of channels.

\section{Multiple-Reach Compatibility and Boundary Conditions}

In the case where several channel reaches are interconnected to form a network, it is necessary to consider the compatibility conditions at junctions where the reaches intersect. Consider an interior or junction node as shown in Figure 3.

The conditions that must be satisfied at such a junction are: 


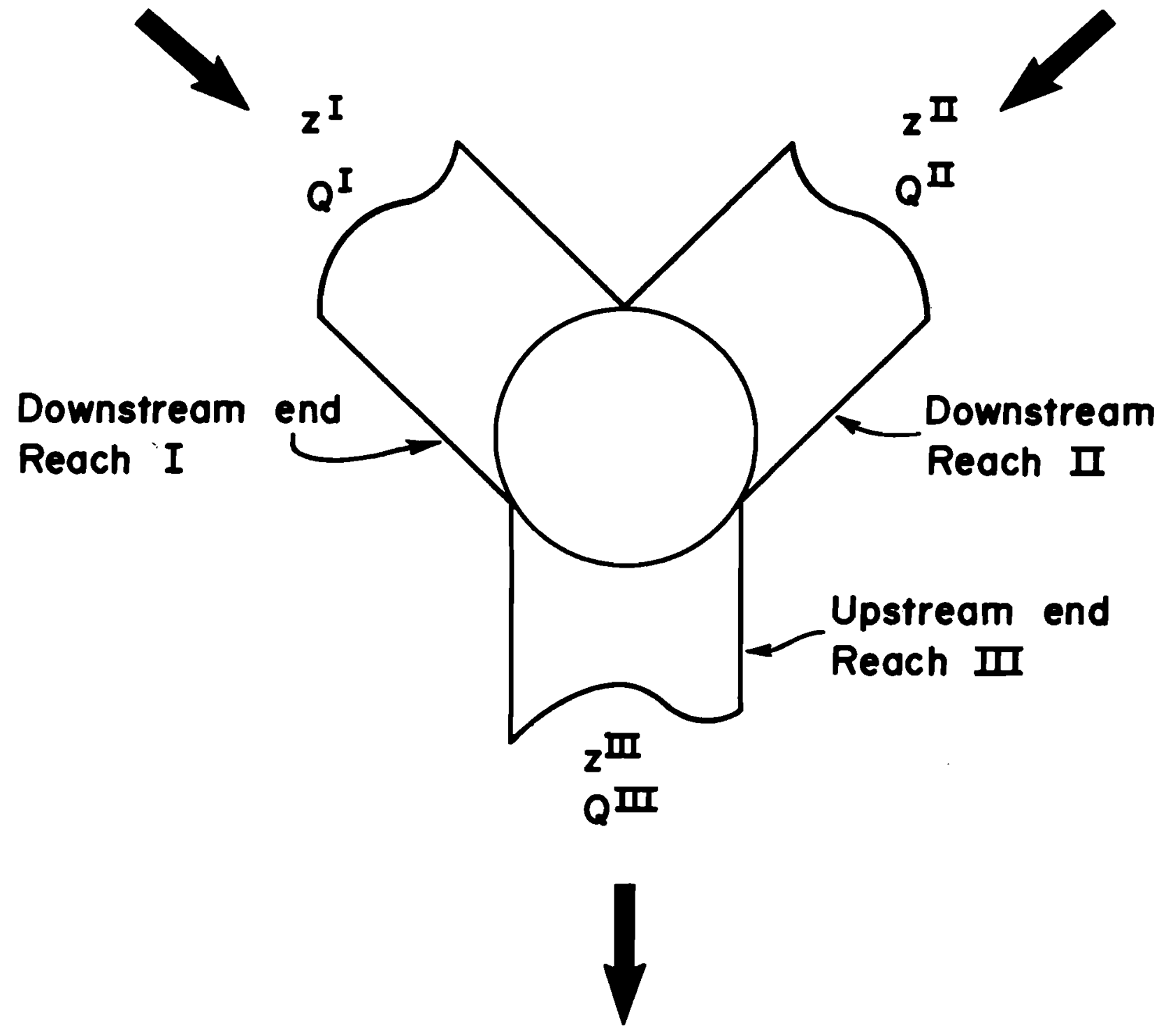

Figure 3. Schematic diagram of an internal node. 
(1) Continuity of mass

$$
\sum_{i=1}^{N} Q^{i}=0 \text { i.e., } Q^{I}+Q^{I I}-Q^{I I I}=0 \text {, }
$$

(2) Kinematic compatibility--constant water surface elevation at junctions

$$
z^{I}=z^{I I}=z^{I I I}
$$

The junction conditions neglect any added losses due to the junction. In order to illustrate the role of these node equations, consider the complete network of channels shown in Figure 4, with boundary conditions as given at the exterior nodes.

The ends of each channel reach defined nodes which are numbered as shown in Figure 4. Reach numbers are also defined in this figure. By following a procedure similar to that which generated Equations (5) and (6), a set of relations involving only unknown values at the nodes can be derived. Letting the nodal values of water surface elevation, $Z$, and discharge, $Q$, be subscripted by the node numbers and superscripted by the reach numbers, these nodal equations can be shown to take the following form:

$\underline{\text { Reach I }}$

$$
\begin{aligned}
& \alpha_{1}^{I} \mathrm{Z}(1)+\alpha_{2}^{I} Q(I)+\alpha_{3}^{I} \mathrm{Z}(3)+\alpha_{4}^{I} Q^{I}(3)=\mathrm{B}^{I}(1) \\
& B_{1}^{I} \mathrm{Z}(1)+\beta_{2}^{I} Q(I)+\beta_{3}^{I} \mathrm{Z}(3)+\beta_{4}^{I} Q^{I}(3)=\mathrm{B}^{I}(2)
\end{aligned}
$$

$\underline{\text { Reach II }}$

$$
\begin{aligned}
& \alpha \frac{I I}{I}(2)+\alpha_{2}^{I I} Q(2)+\alpha \frac{I I}{z}(3)+\alpha \frac{I I}{4} \Omega^{I I}(3)=B^{I I}(1) \\
& \beta \frac{I I}{I} Z(2)+\beta \frac{I I}{2}(2)+\beta \frac{I I}{3} Z(3)+\beta{ }_{4}^{I I} Q^{I I}(3)=B^{I I}(2),
\end{aligned}
$$

$\underline{\text { Reach III }}$

$$
\begin{aligned}
& \alpha_{1}^{\operatorname{III}} z(3)+\alpha_{2}^{\operatorname{III}} \operatorname{III}_{(3)}+\alpha_{3}^{\operatorname{III}} z(4)=\alpha_{4}^{\operatorname{III}} Q(4)={ }_{B} \operatorname{III}
\end{aligned}
$$

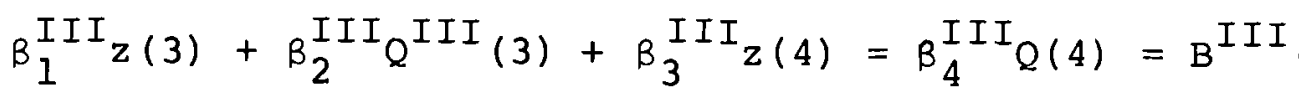




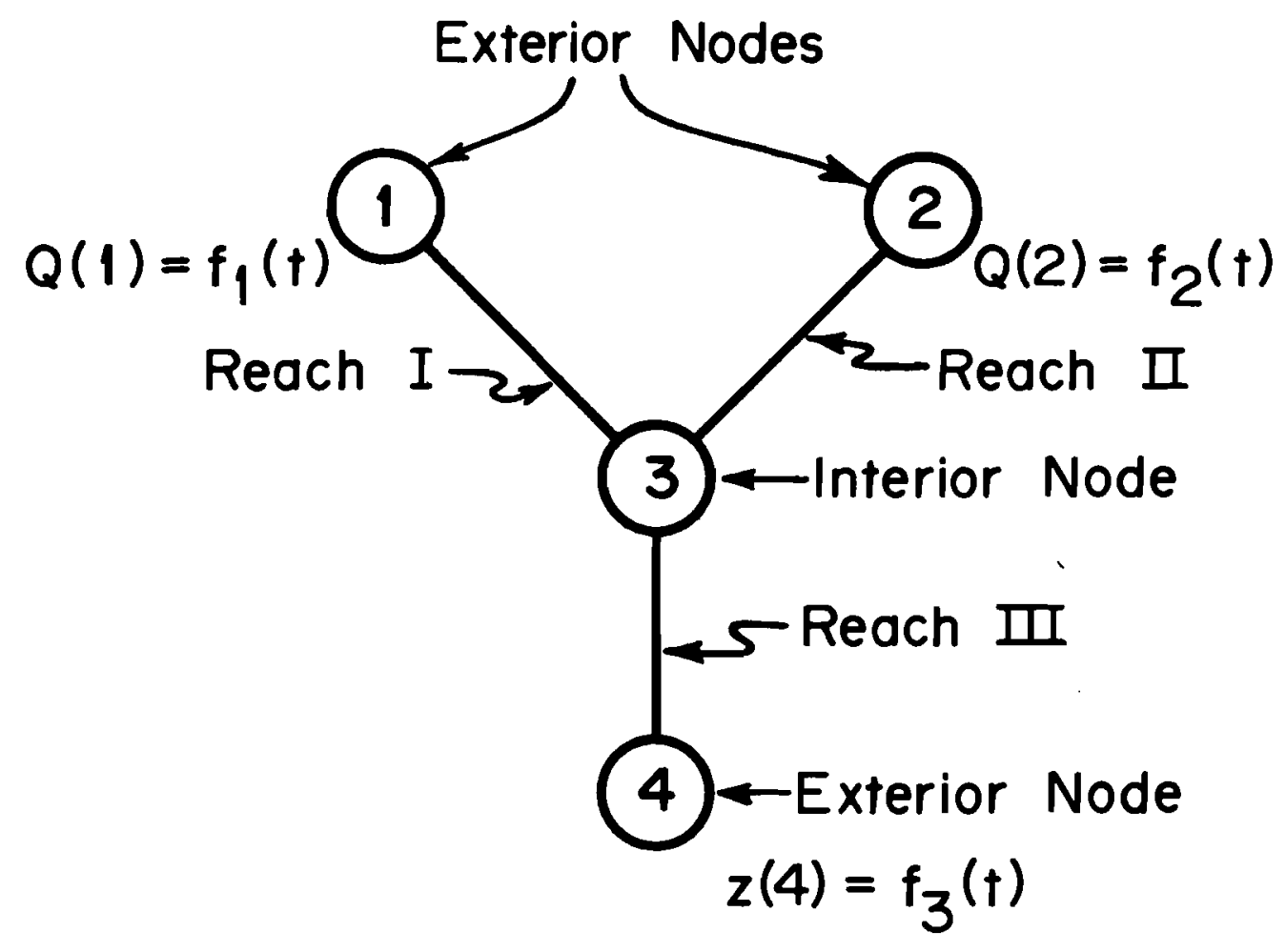

Figure 4. Simple Y network. 
where the $\alpha^{\prime} s$ and $\beta^{\prime} s$ are defined for their appropriate reaches by Equations (5) and (6).

(3). Hence

It is also necessary to satisfy continuity at junction

$$
Q^{I}(3)+Q^{I I}(3)-Q^{I I I}(3)=0 \text {. }
$$

At the exterior nodes, the boundary conditions as a function of $\mathrm{Z}$ or $\Omega$ are also shown in Figure 4 . Hence

$$
\begin{aligned}
& Q(1)=f_{1}(t) \\
& Q(2)=f_{2}(t) \\
& z(4)=f_{3}(t) .
\end{aligned}
$$

In Equations (9), (10), (12), and (13) there are ten unknowns and ten equations. The external coefficient matrix formed by these equations is shown in Figure 5 . Solving the external coefficient matrix, the nodal water surface elevations and discharges can be determined. The values at the interior points are then determined by backsubstituting in Equations (4a) and (4b).

\section{Initial Conditions}

For many cases of river flows, initial conditions of $Z$ and $Q$ are not explicitly available. Often an initial condition of steady state is assumed for purposes of analysis. However, this is usually an arbitrary choice which is unlikely to be realized in practice; hence the initial conditions must be arbitrarily assumed. If the transient flow period is much longer than the period over which the initial conditions have effect, then a significant portion of the transient can still be predicted accurately, irrespective of the assumed initial conditions.

The implications of this argument for computer programming are as follows. First, a complete set of initial conditions must be provided; these can take the form of known or estimated water surface elevation and discharge at each discretized point of the channel. Second, there is no need to provide a special routing for computing steady state profiles. Such profiles can be obtained by starting from an arbitrary, yet realistic, profile, and letting the resulting transients decay while holding the boundary conditions at fixed values for a sufficient period of time. The implicit formulation is particularly useful in this respect because of its ability to take large time steps. 


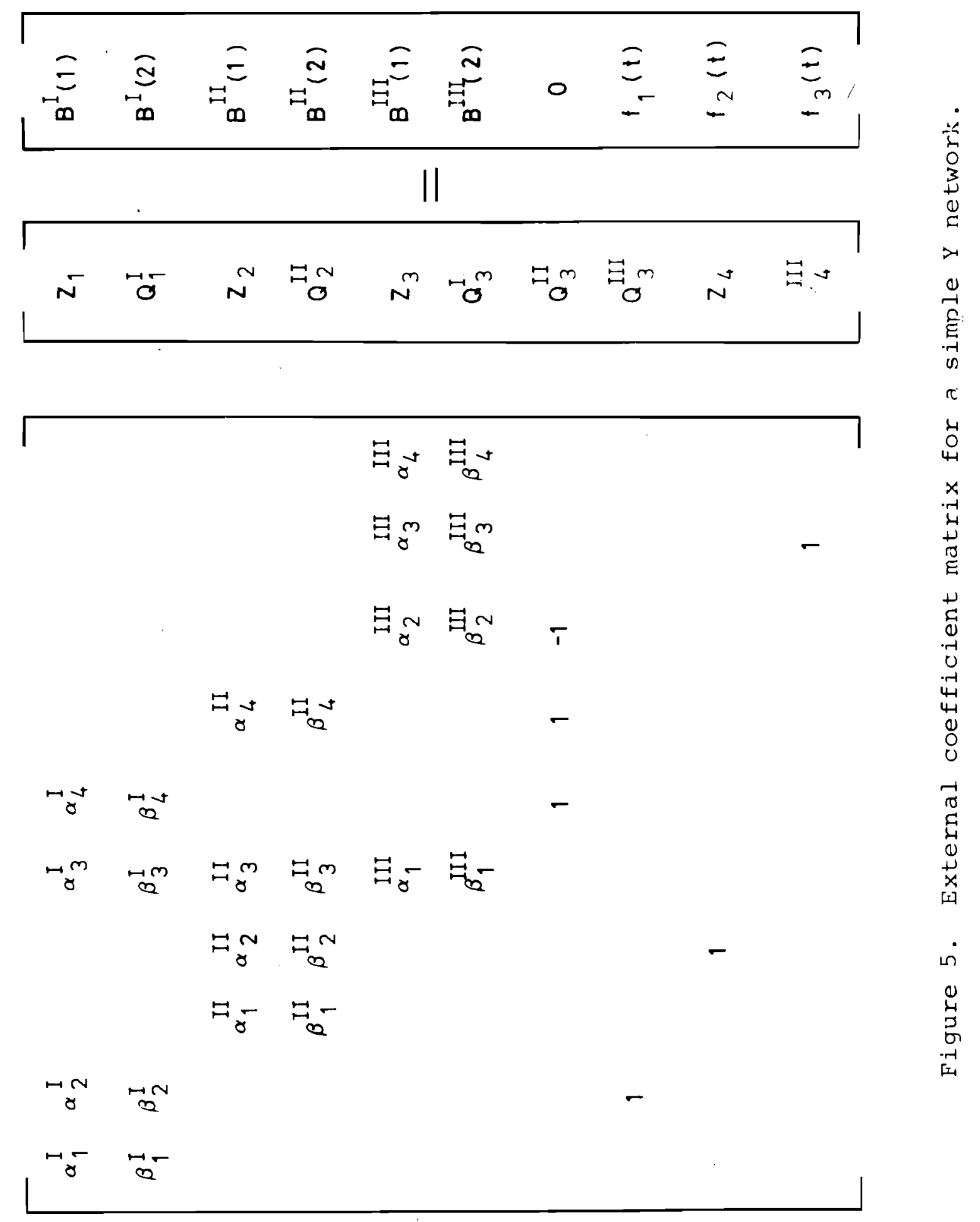


Modelling of Channel Structures

Structures that can affect the transients being studied, often exist in river networks. They include small dams, locks, and bridges. The proposed network formulation allows these structures to be studied either by the inherent nature of modelling the network into different reaches, or by including the equations of flow through the structure in the external coefficient matrix. The latter method was used to study the effect of bridges on flood transients where the water can back up and overtop the structure (Wood [7]). Essentially the bridge is considered a reach and the appropriate equations governing the head loss through the bridge (assuming no storage since the reach is very short) are used in the external coefficient matrix. A future paper will describe this methodology in detail. The flexibility of the network formulation due to the external coefficient matrix concept has greatly increased its usefulness for general-purpose modelling.

Application to the Hydraulic Model of the James River at the U.S. Army Corps of Engineers Waterways Experiment Station

The computational scheme presented herein was applied by Dailey and Harleman [1] to calculate the hydraulic parameters for a water quality model. The hydraulic model simulated the behavior of a small-scale physical model of the James River. A location map of the James River is shown in Figure 6. The length of the estuary is about 100 miles, and the simulation model used a network of twenty-six reaches and twenty-four nodes, shown in Figure 7 , to represent the behavior of the James River hydraulic model. The parameters used in the schematization are listed in Table 1. The fresh water inflows, given in Table 2 , were assigned to the appropriate reaches, and a tide consisting of a sinusoidal wave, with a range that closely matched the measured range at the nearby Hampton Roads gage, was imposed as the ocean boundary. The results, shown in Figures 8 through 11 , compare extremely well with those found by the physical model, not only in tide ranges but also in lag times, which are in the order of six hours.

\section{Application to Cork Harbour, Ireland}

Dailey and Harleman [1] also applied the network formulation using the six-point finite difference scheme to the Cork Harbour, Ireland, estuary. Cork Harbour has a main channel of approximately eighteen miles between the ocean and the city of cork. The layout, with the reach-node connectivity, is shown in Figure 12. The results are most interesting because the prototype was modelled as a thirteenreach double-looped network. Tide predictions are published for Cork and Cobh, with spring tide ranges of 11.9 feet and 


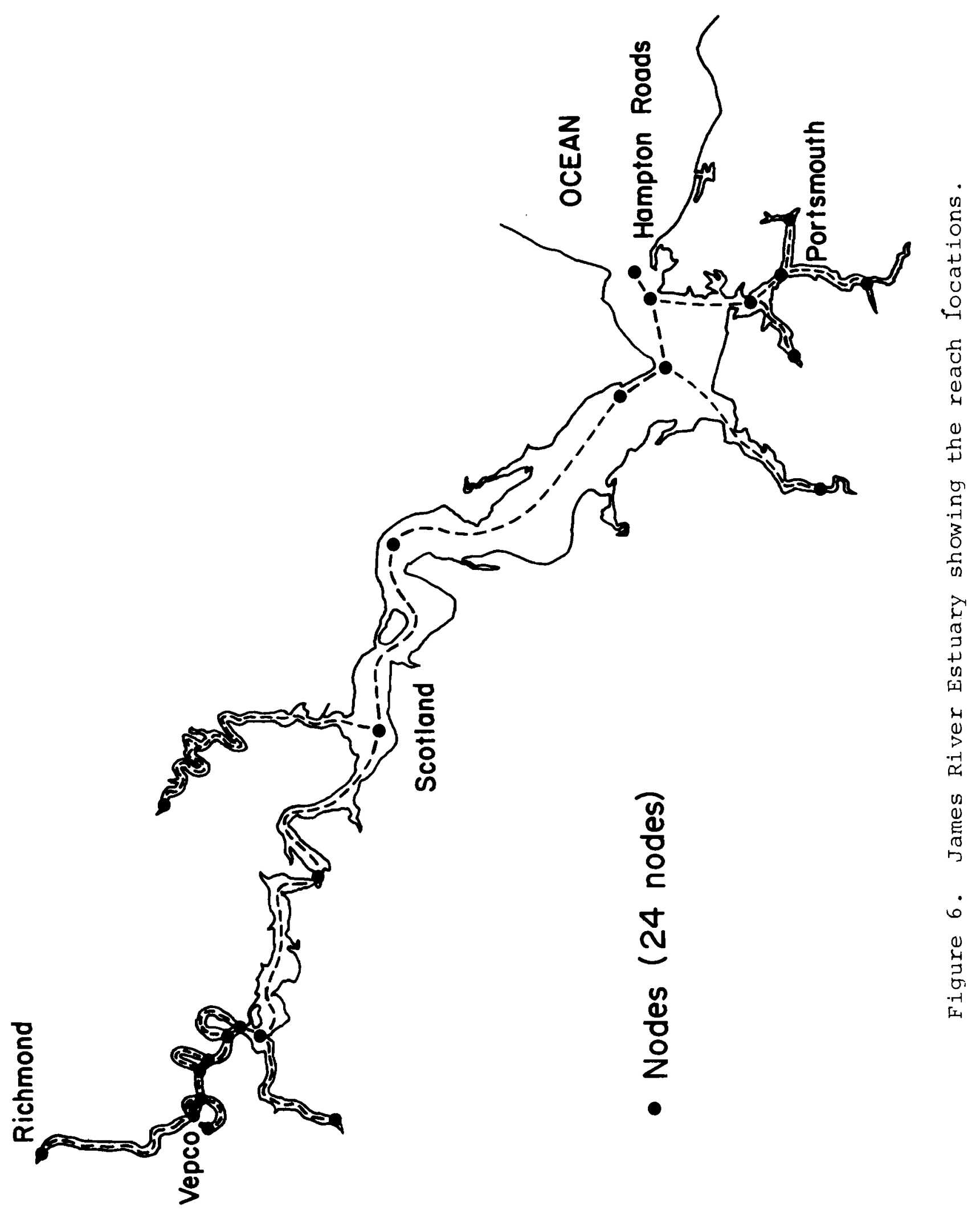




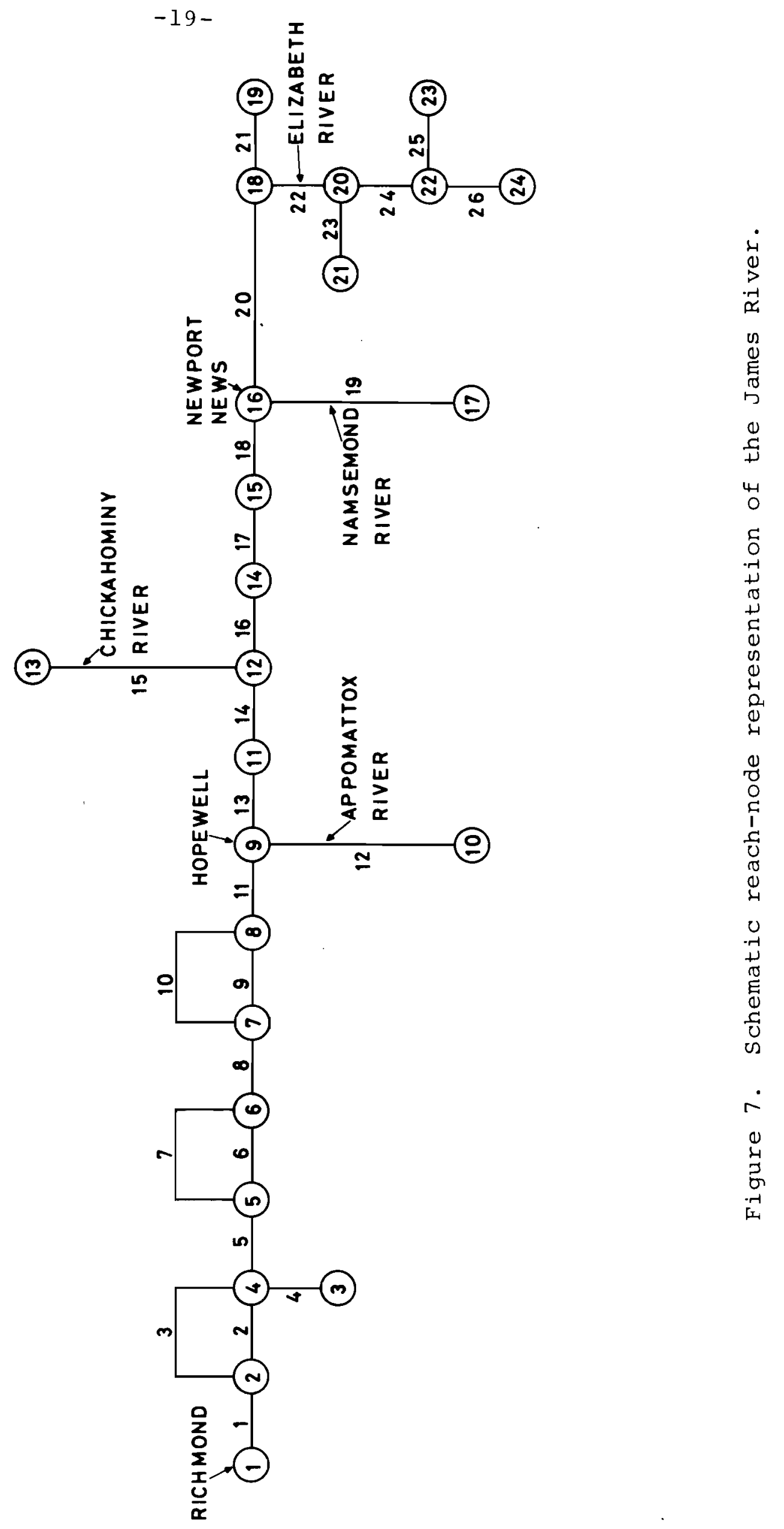


Table 1. James River model schematization parameters in model units

(from Dailey and Harleman [1])

\begin{tabular}{|c|c|c|c|c|}
\hline Reach & $\begin{array}{c}\text { Upstream } \\
\text { Node }\end{array}$ & $\begin{array}{l}\text { Downstream } \\
\text { Node }\end{array}$ & Hydraulic $\Delta x$ & $\begin{array}{l}\text { Manning } \\
\text { Coefficient }\end{array}$ \\
\hline 1 & 1 & 2 & 4.18 & .028 \\
\hline 2 & 2 & 4 & 1.73 & .028 \\
\hline 3 & 2 & 4 & 2.10 & .028 \\
\hline 4 & 4 & 3 & 2.52 & .028 \\
\hline 5 & 4 & 5 & 1.88 & .028 \\
\hline 6 & 5 & 6 & 1.57 & .028 \\
\hline 7 & 5 & 6 & 2.01 & .028 \\
\hline 8 & 6 & 7 & 2.14 & .028 \\
\hline 9 & 7 & 8 & 0.74 & .028 \\
\hline 10 & 7 & 8 & 2.32 & .028 \\
\hline 11 & 8 & 9 & 1.90 & .028 \\
\hline 12 & 9 & 10 & 3.05 & .028 \\
\hline 13 & 9 & 11 & 3.09 & .025 \\
\hline 14 & 11 & 12 & 4.17 & .025 \\
\hline 15 & 12 & 13 & 5.09 & .035 \\
\hline 16 & 12 & 14 & 5.19 & .020 \\
\hline 17 & 14 & 15 & 5.09 & .020 \\
\hline 18 & 15 & 16 & 4.63 & .020 \\
\hline 19 & 16 & 17 & 5.45 & .025 \\
\hline 20 & 16 & 18 & 5.51 & .020 \\
\hline 21 & 18 & 19 & 3.26 & .020 \\
\hline 22 & 18 & 20 & 5.10 & .025 \\
\hline 23 & 20 & 21 & 5.58 & .028 \\
\hline 24 & 20 & 22 & 2.80 & .028 \\
\hline 25 & 22 & 23 & 4.66 & .028 \\
\hline 26 & 22 & 24 & 5.15 & .028 \\
\hline
\end{tabular}


Table 2. Constant fresh water inflows for the James River model in prototype units. ( from Dailey and Harleman [1])

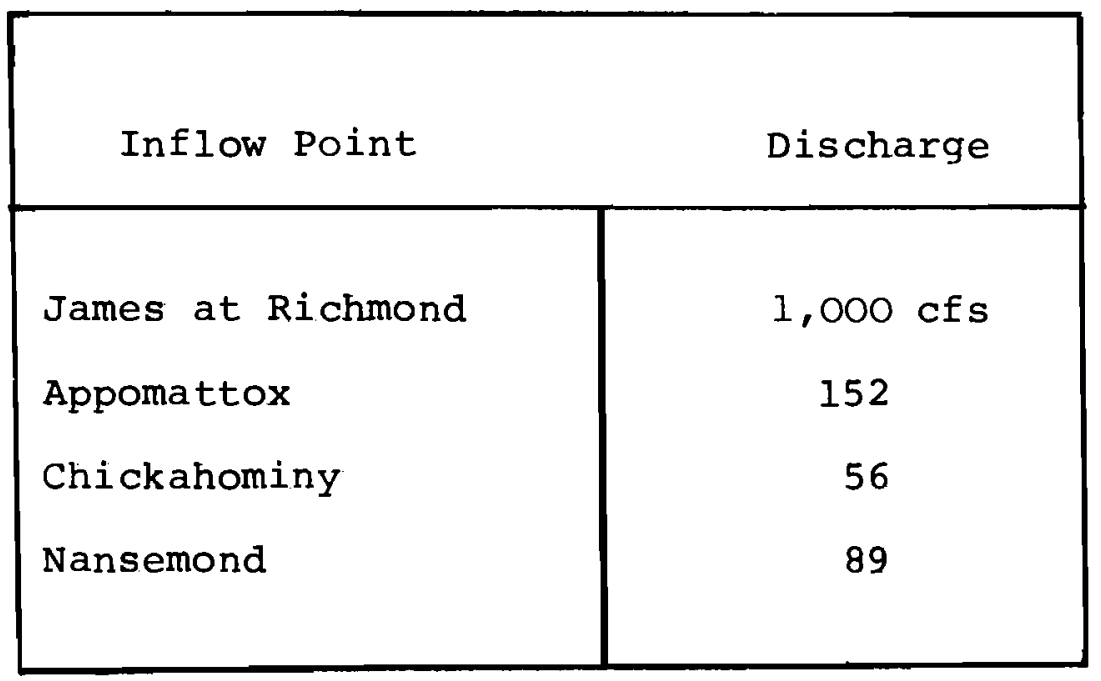




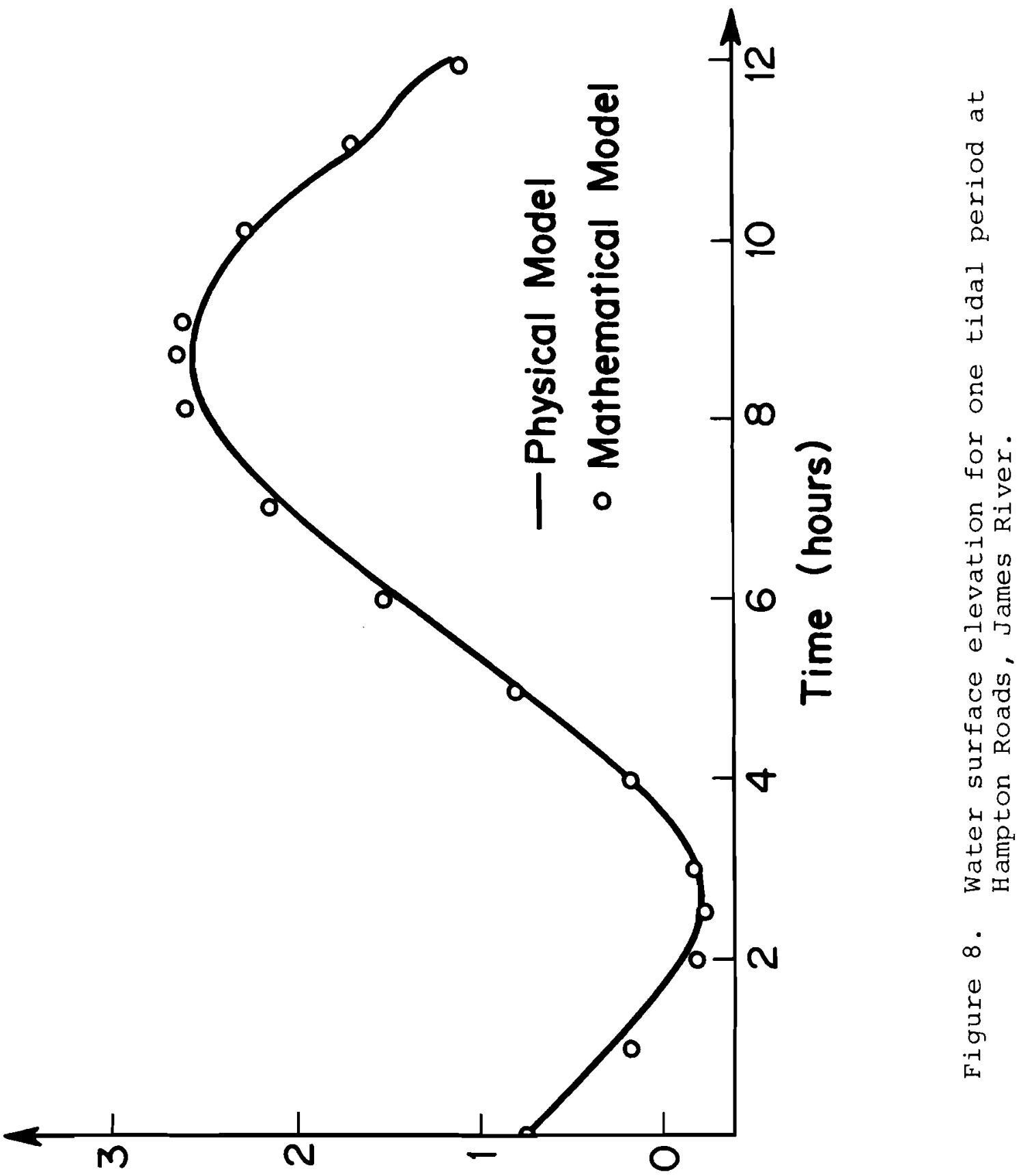

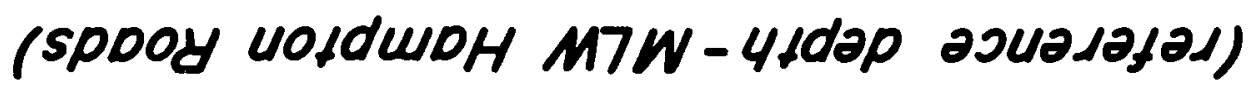

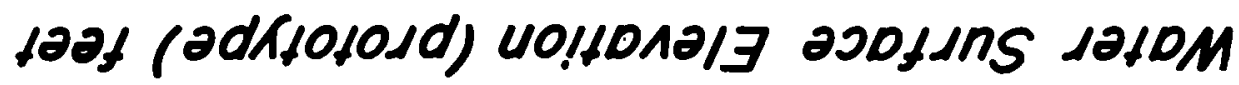




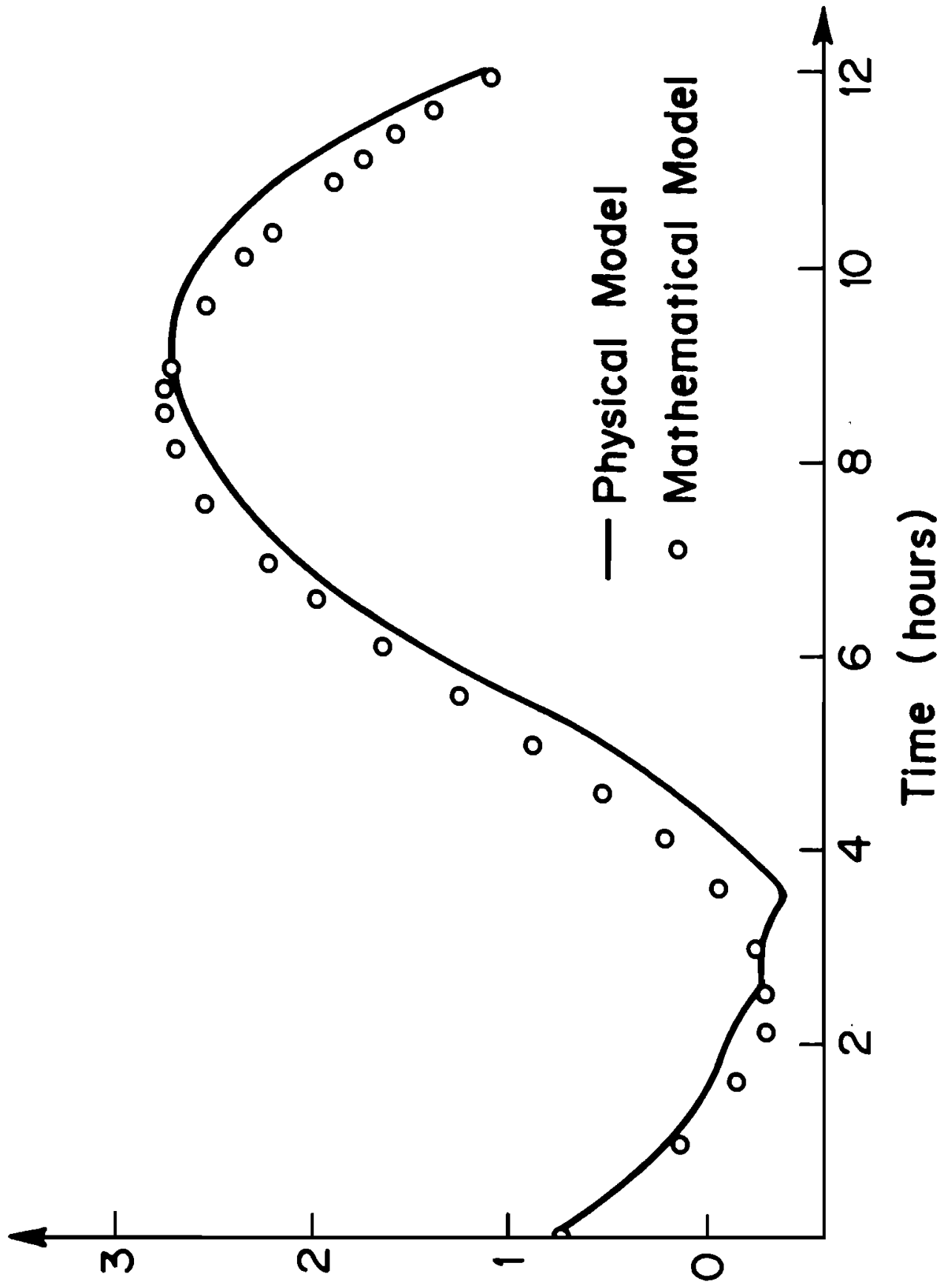

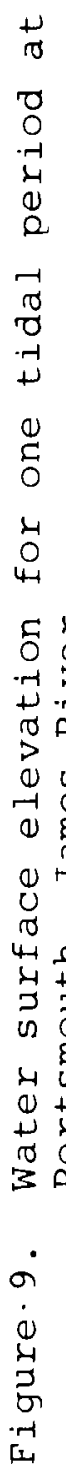

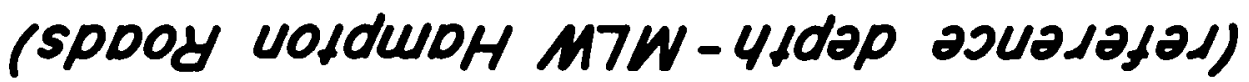

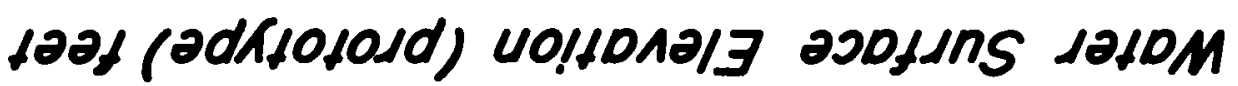




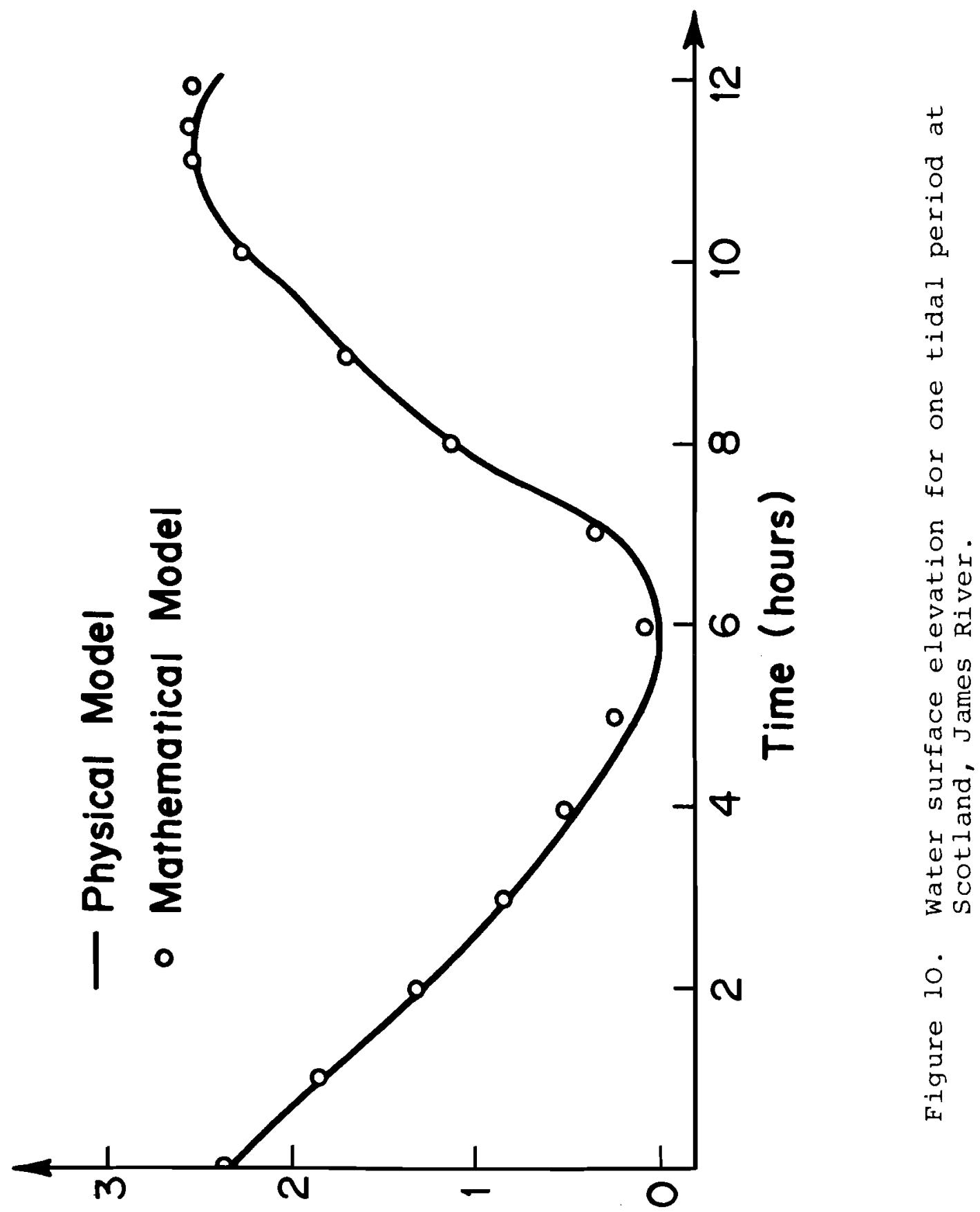

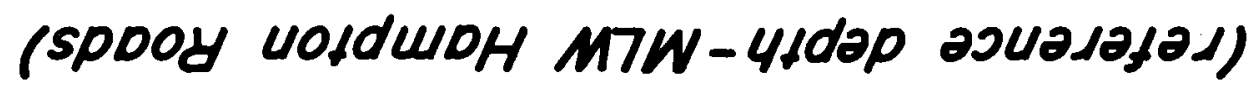

lo2f (OdK10101d) U0!1012/3 2001/nS 1210M 


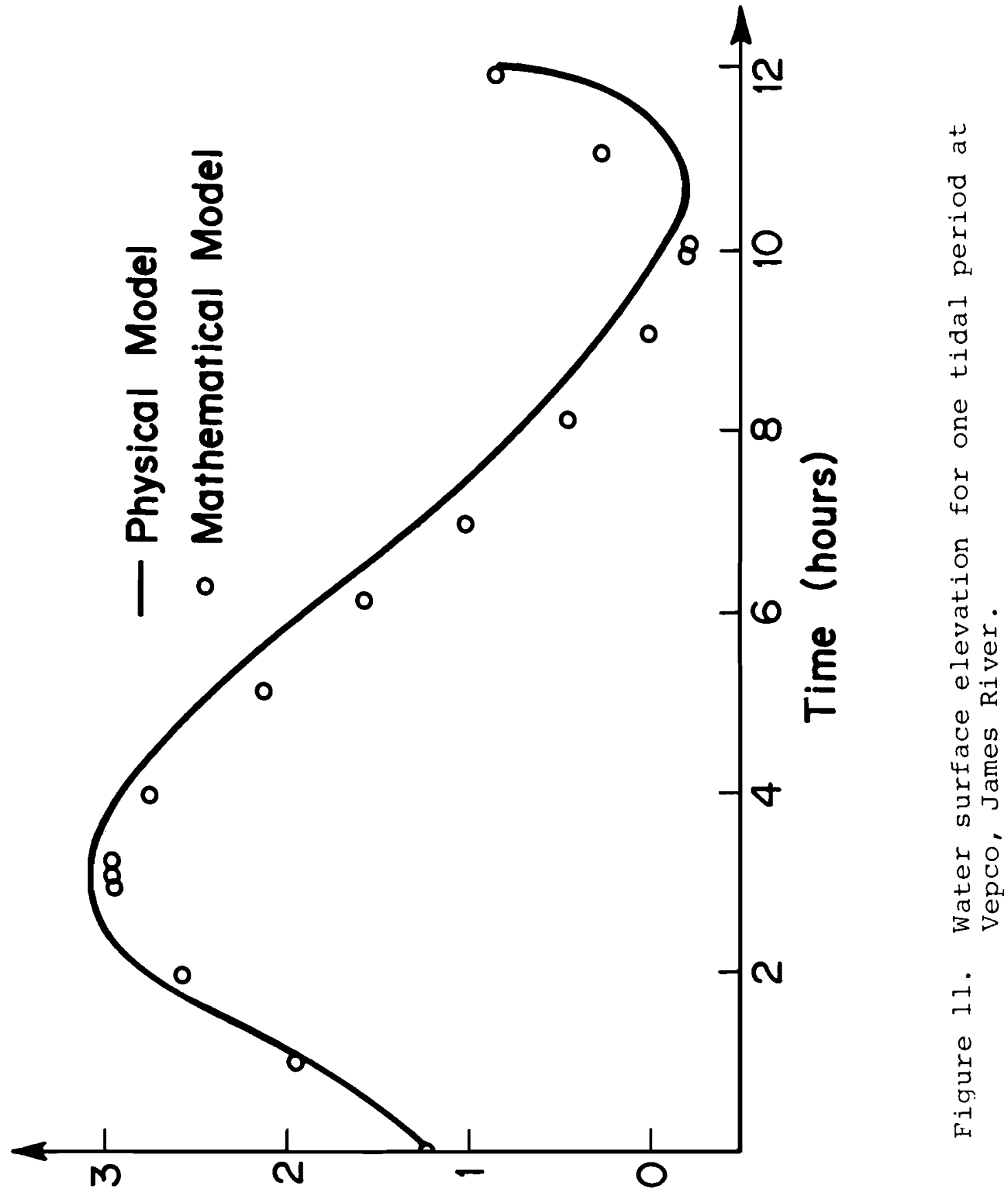

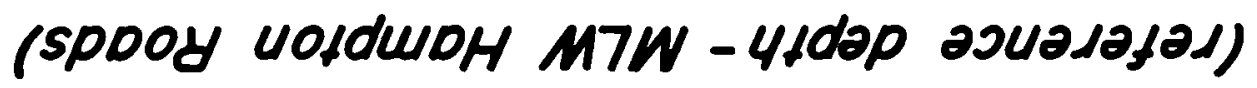

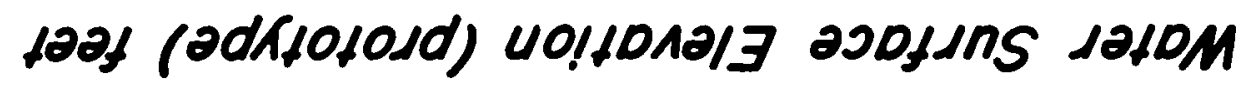




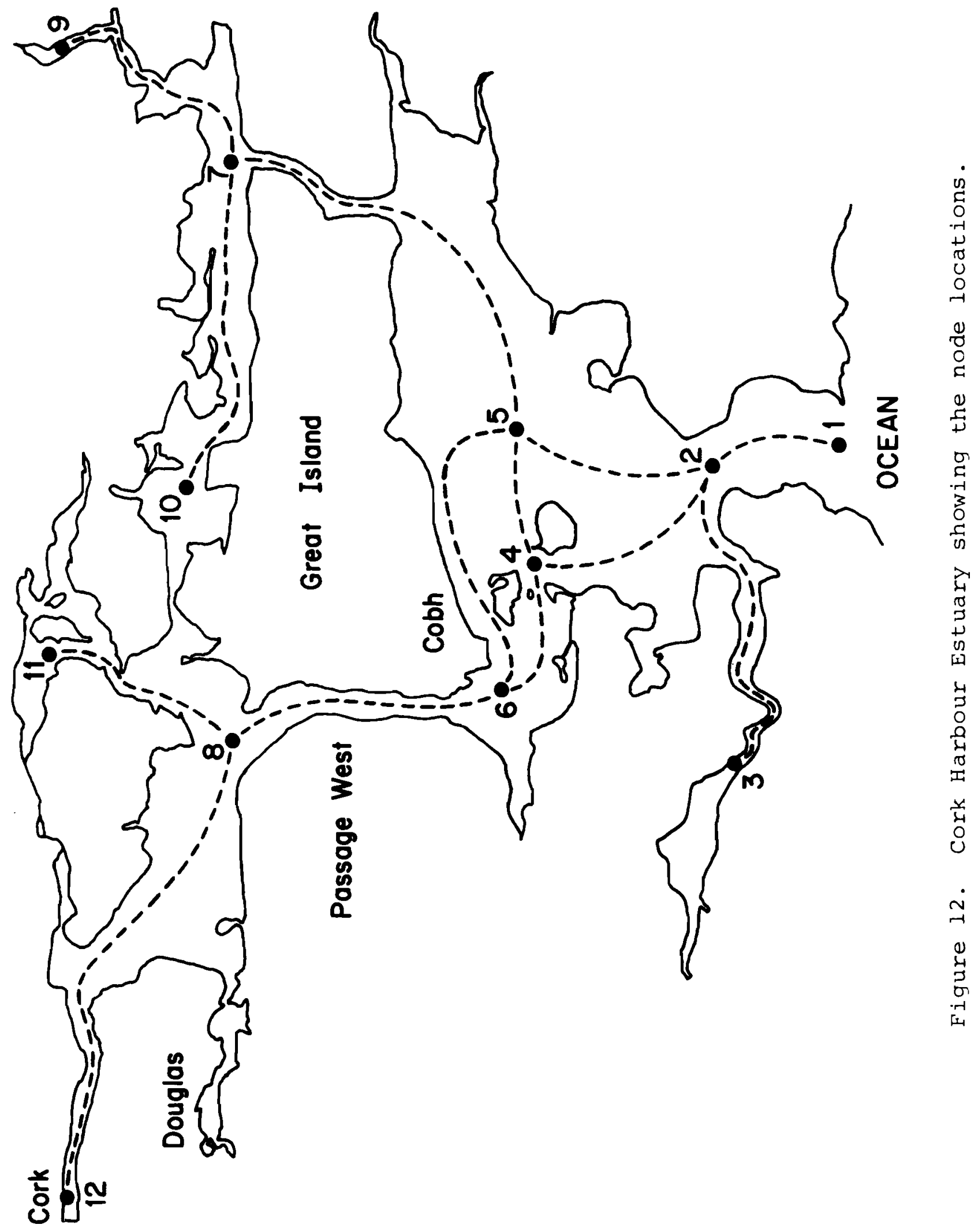


12.9 feet respectively and a time lag of about twenty minutes. O'Kane [4] estimates peak discharges of 100,000 cfs for Passage West and 400,000 cfs for the ocean entrance under spring ride conditions. The mathematical model used a semi-diurnal tide with a range of twelve feet for an ocean boundary. A Manning coefficient of 0.025 was estimated for each reach. Under the extremely complex geometry, the model results presented in Figures 13, 14, and 15 compare favorably with known information.

\section{Rio Bayamon, Puerto Rico}

A four-point finite difference formulation for the solution of flow networks has been applied in the simulation of the lower reaches of the Rio Bayamon in Puerto Rico. The network lies in the coastal plain and was modelled as shown in schematic form in Figure 16. The Bayamon basin is approximately 100 square miles in area and the runoff for various storm events was simulated using the M.I.T. Catchment Mode. These values were then input to the flood router model at nodes 5,9 , and 10 as shown in Figure 16 . The dry-weather discharge values are close to zero for all reaches in the network, and the river can obtain peak flood discharges in the order of $100,000 \mathrm{cfs}$ in Reach 1 with a rise time of approximately three hours. During dry weather flows, the discharge in the network does not normally flow in Quebrada Aquas Frias (Reach 8). During flood events, Reach 2 exceeds bank capacity and flows down Quebrada Aquas Frias, whose flow conveyance above overbank is quite large. The flow from Reach 2 into Quebrada Aquas Frias is facilitated by the inability of Reach 3 to handle the large flows from Reach 2 due to the inputs of the Rio Hondo and Quebrada Catalina in conjunction with the conveyance of the lower Rio Bayamon. Early flows from the Hondo and the Catalina often raise the water surface elevation at Node 7 which can lead to a reversal of flow in Reach 3 and down Quebrada Aquas Frias.

The network formulation of the routing model effectively simulated these events. Figures 17, 18, and 19 present hydrographs and water surface profiles for a number of reaches. No accurate flood-discharge or elevation measurements are recorded, but from the available information, it appears that the current model represents the peak-discharge and water-surface profile histories to a satisfactory degree.

Figure 17 indicates both the input rainfall to the basin and the discharge hydrographs for Reaches 1, 2, and 8. Note that the peak input discharge of 73,000 cfs is attenuated to 43,000 cfs at the lower end of Reach 2. It is further reduced by the remaining part of the network to a peak of $10,000 \mathrm{cfs}$ at the lower end of Quebrada Aquas Frias (see 


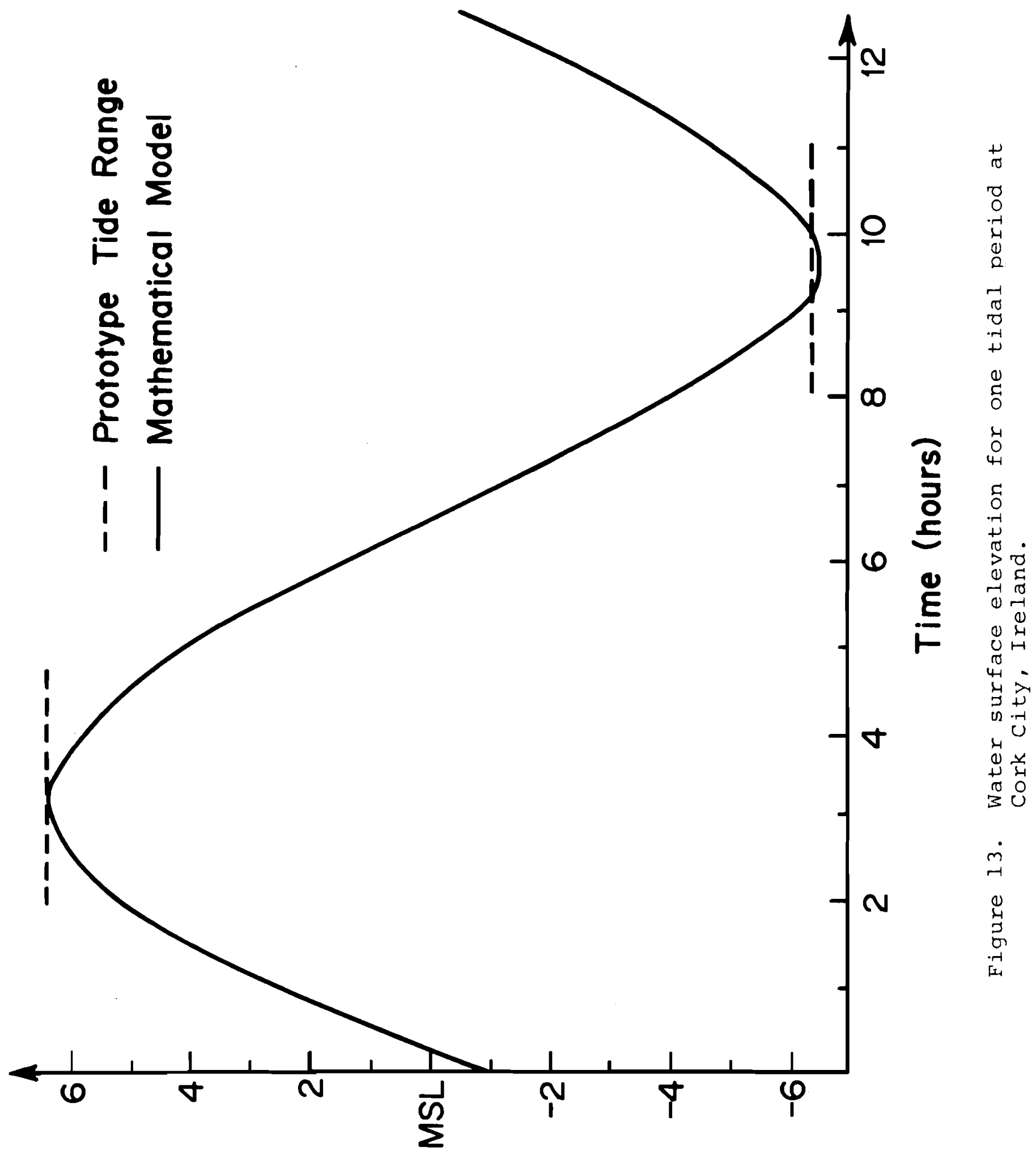

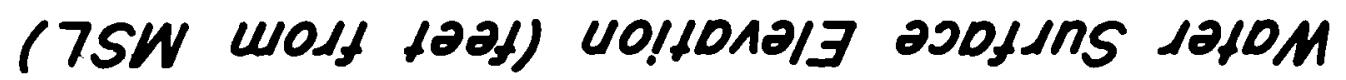


Water Surface Elevation (feet from MSL)

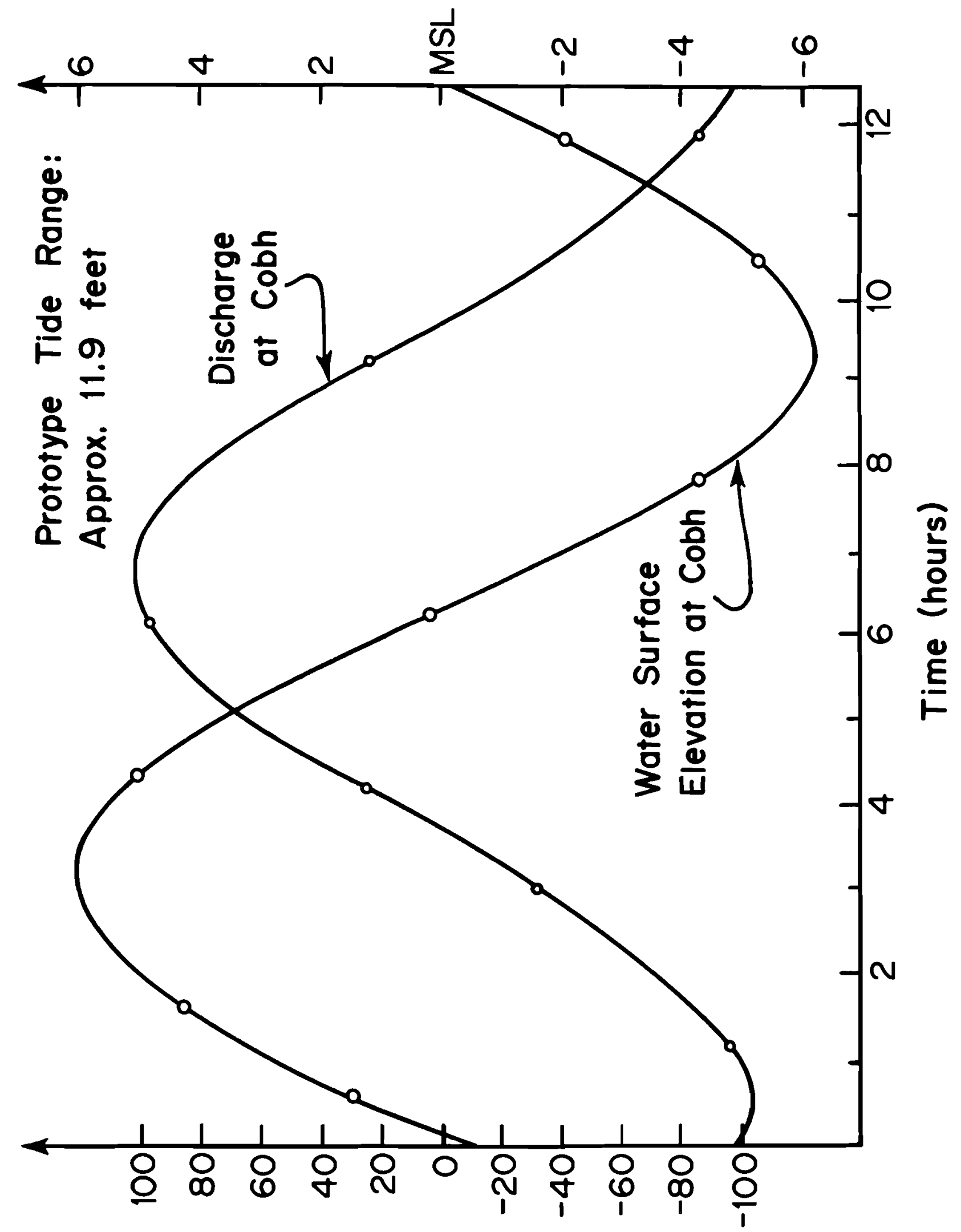




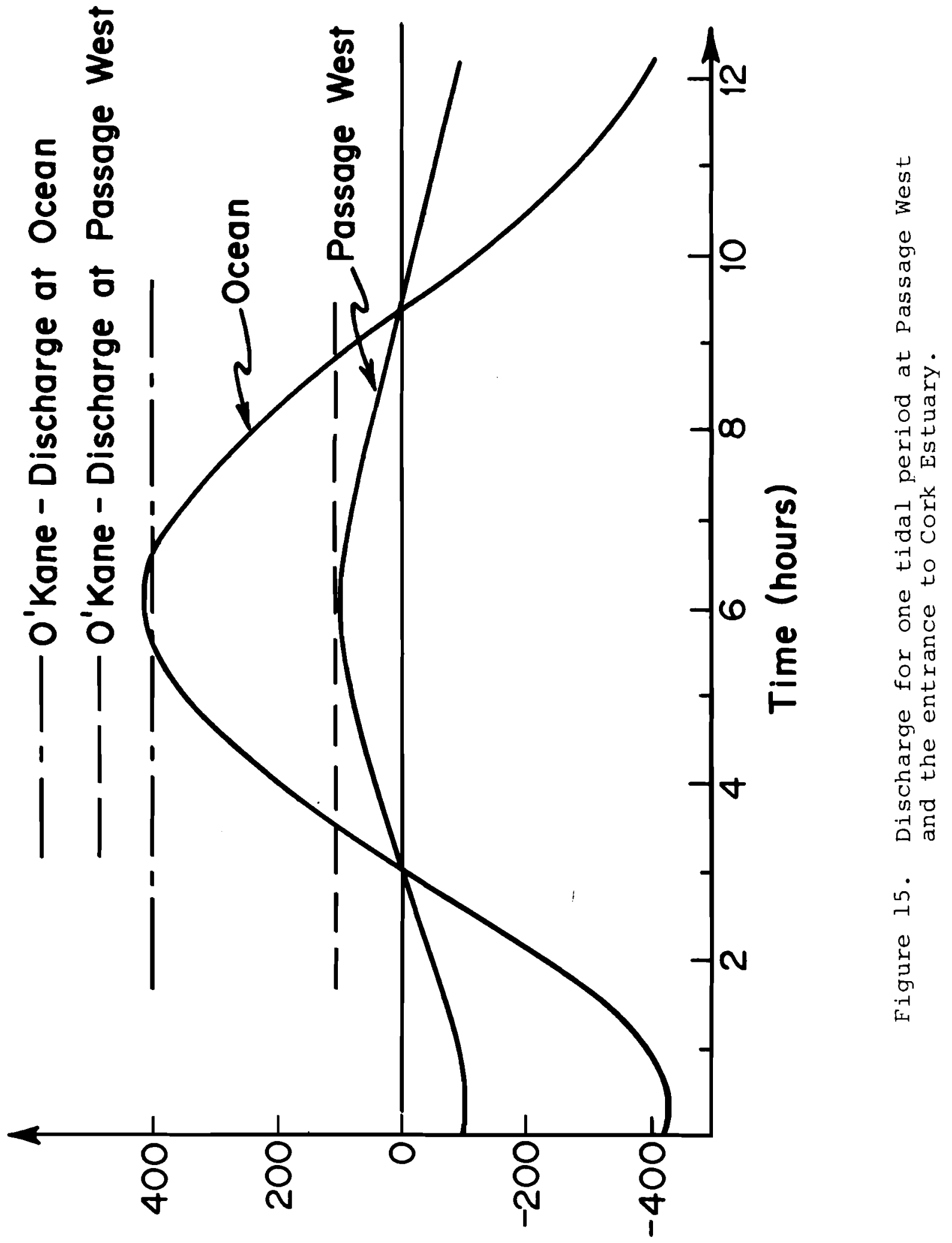

$(5100006 x)$ 261040510 


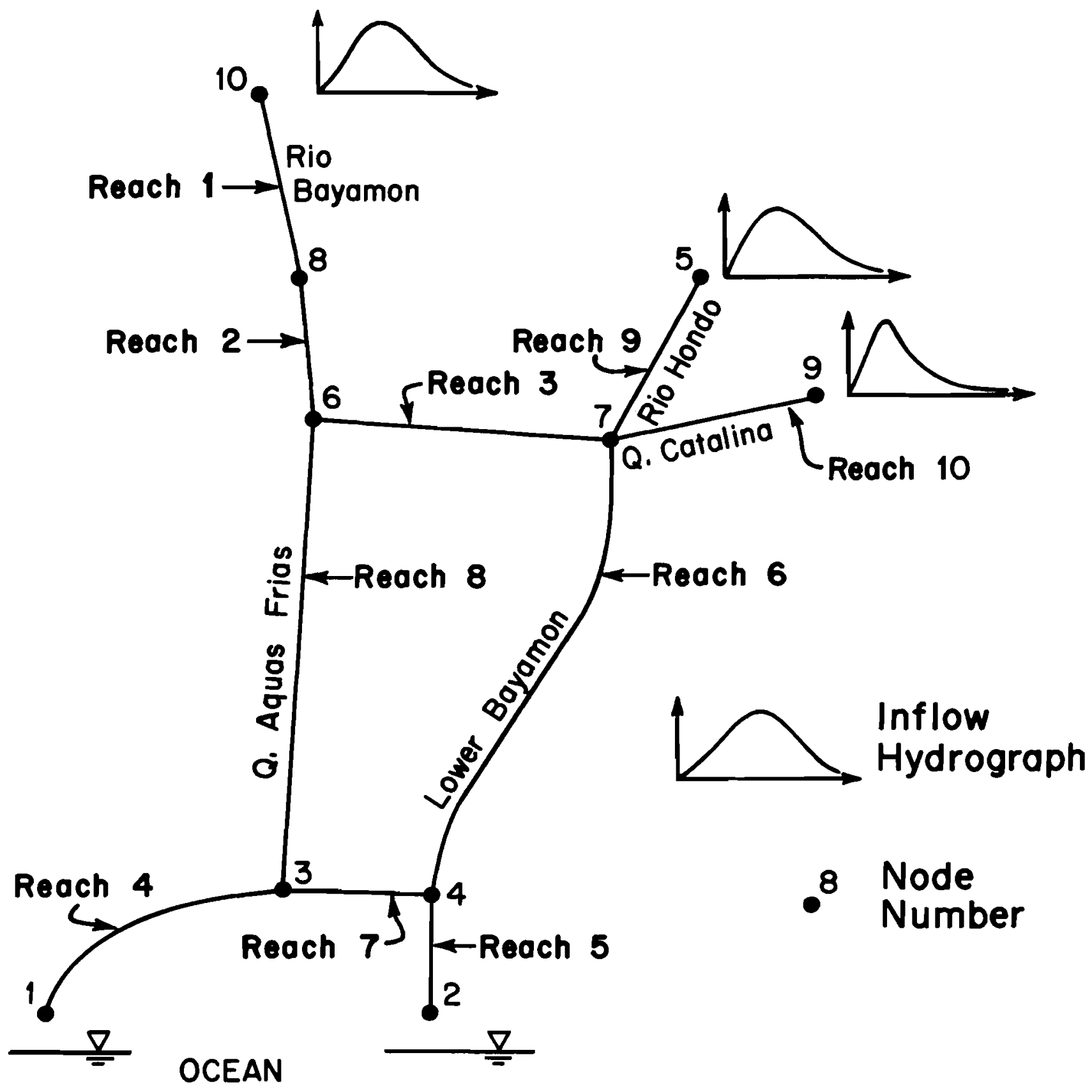

Figure 16. Schematic diagram of the reach-node representation of Rio Bayamon, Puerto Rico. 
Discharge ( $\times 1000$ cfs)

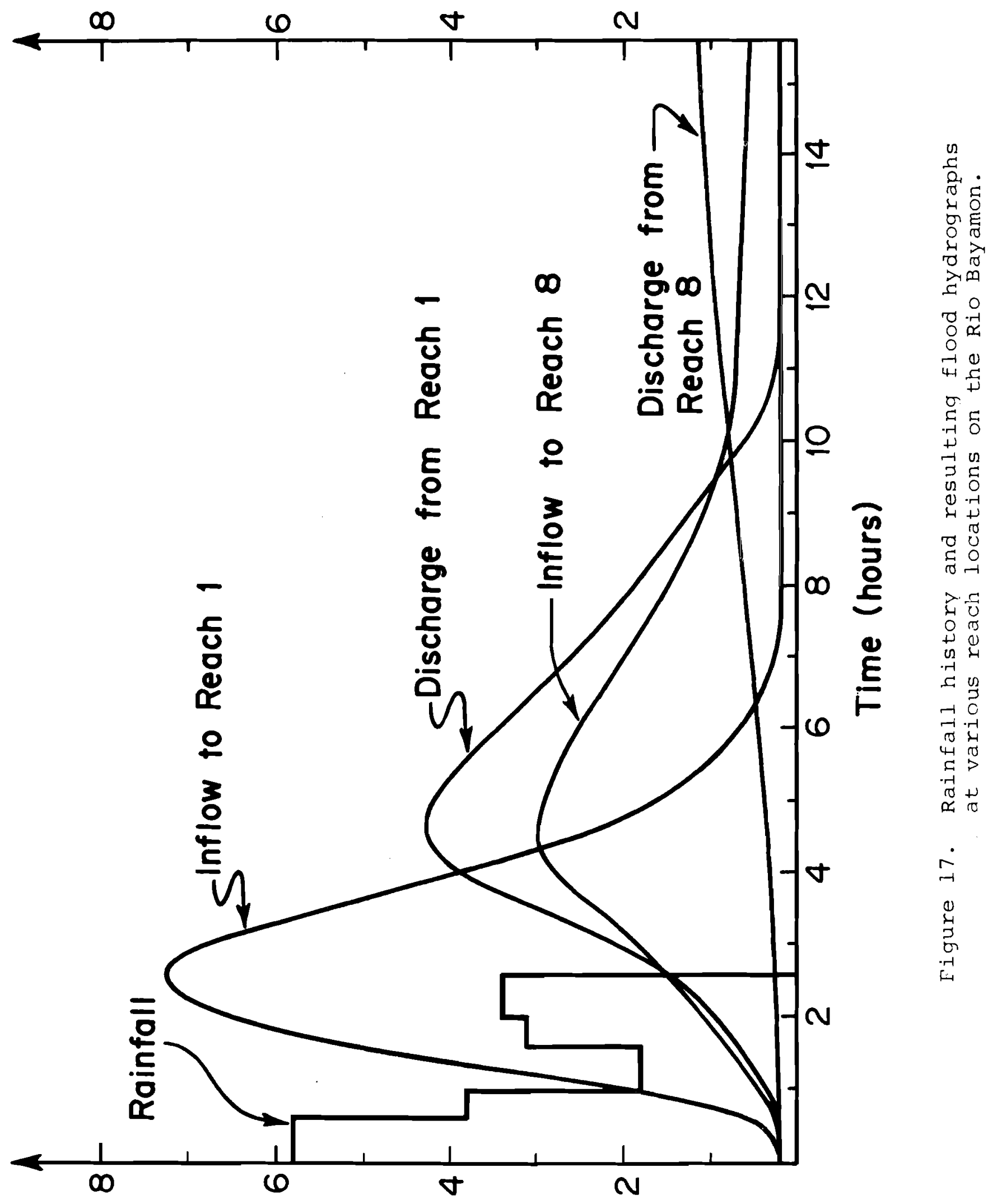

(14/4!) Rt!suatul /lofu!nd 


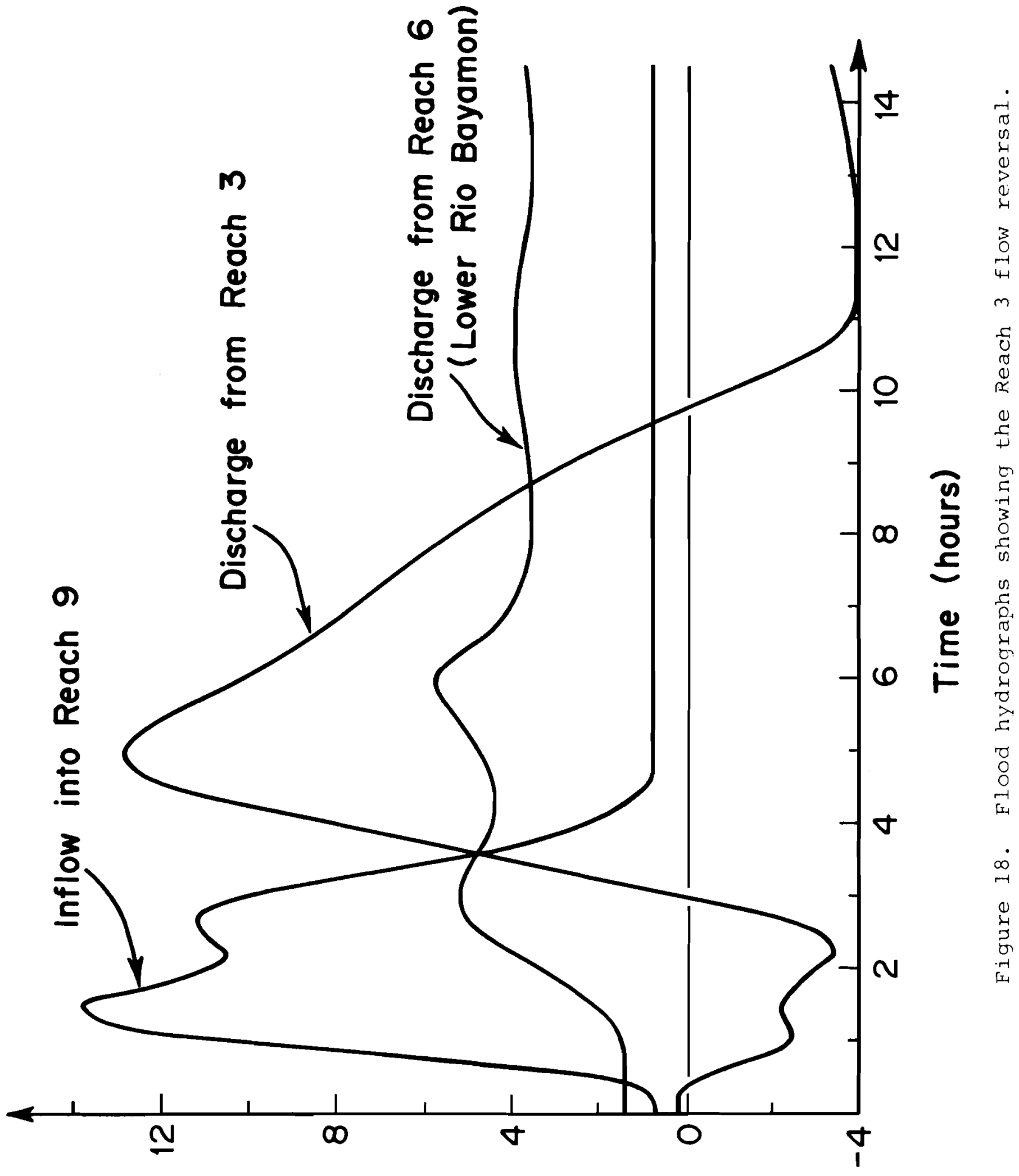

$(5,00001 x)$ 2610405!O 


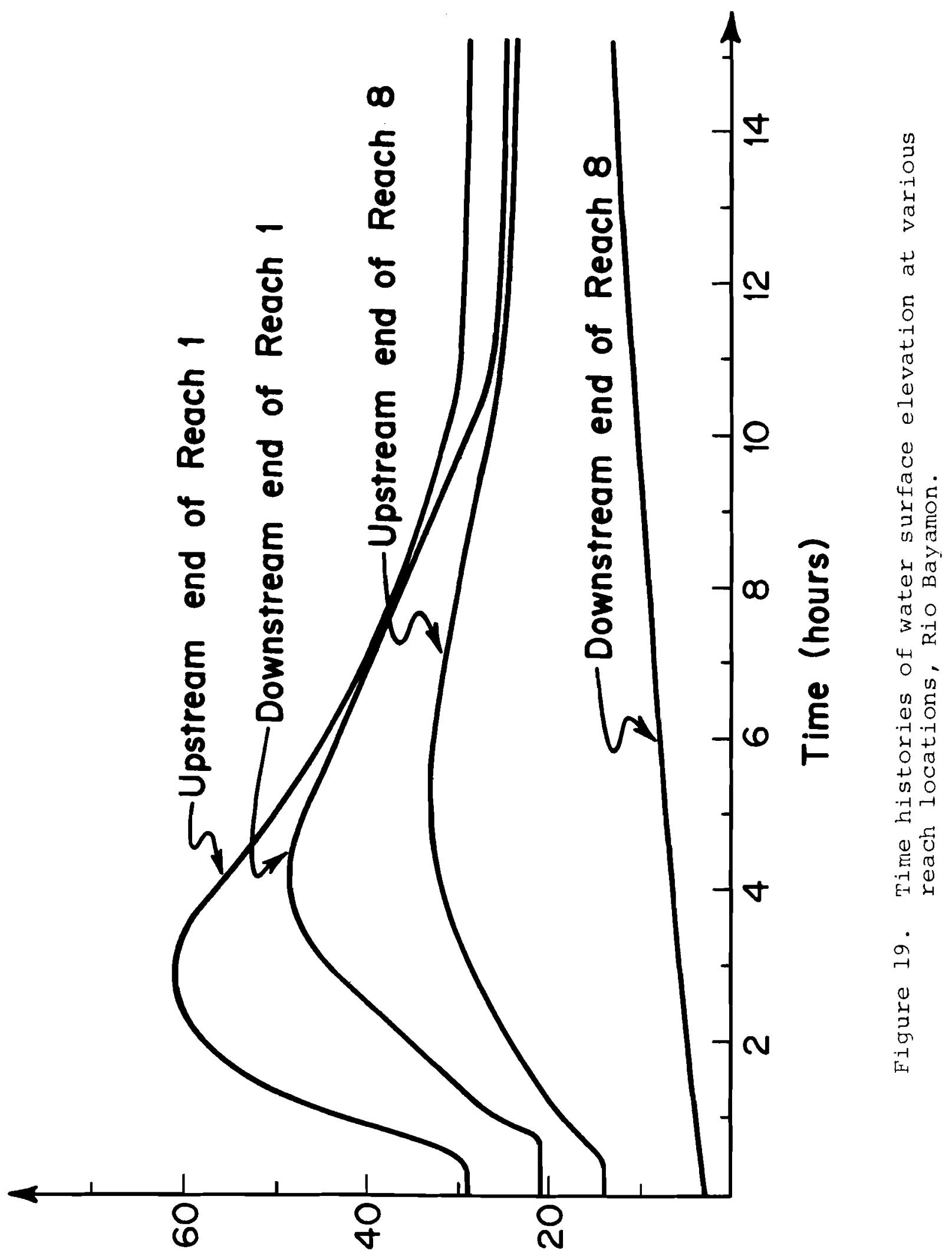

(120\&) 40/1012/3 200\&1/ns 1210M 
Figure 18). The peak discharges to the ocean were 3200 cfs for Reach 4 and 13,300 cfs for Reach 5. Corresponding water surface elevation profiles are presented in Figure 19.

\section{Computation Time}

As was mentioned earlier, the banded nature of the interior coefficient matrix, $A$, allows rapid solutions. The external coefficient matrix is, for most problems, quite small. If the nodes are carefully numbered, the external matrix can also be treated as a sparse-banded matrix. The solution procedures reveal that the computation time mostly depends on the number of meshpoints, $\Delta X^{\prime} s$, in the network and not on the number of reaches. This is so because the solution of the interior coefficient matrix and the backsubstitution from the nodal water surface elevations and discharges depend upon the total number of meshpoints, and only the inversion of the external coefficient matrix depends upon the number of reaches.

One test, consisting of two reaches and a total of 100 mesh points, and running for almost 200 time steps, was executed in about. 1 minute on an IBM 360/195. This included disk storage of about twenty-three profiles and hydrographs.

\section{Summary}

The network formulation presented here appears to have sufficient flexibility to allow modelling of the various river and estuary networks which are of practical interest. Due to the network formulation structure with an interior coefficient matrix for each reach and an external coefficient matrix for the networks, it is possible to incorporate special features such as bridges, small dams, and locks into the simulation analysis. This is obtained either by the inherent nature of modelling the network or by including special equations of flow through the structure of the matrices.

The formulation of the internal and external matrices allows for efficient computation. This is so because the solution of the interior coefficient matrix and the back substitution from the nodal water surface elevations and discharges depend upon the total number of meshpoints and only the inversion of the external coefficient matrix depends upon the number of reaches.

The network formulation also allows ready modification of the particular finite difference scheme used to solve the transient routing problem within each reach of the network. 


\section{References}

[1] Dailey, James E., and Donald R.F. Harleman, "Numerical Model for the Prediction of Transient Water Quality in Estuary Networks," Report No. 158 Ralph M. Parsons Laboratory for Water Resources and Hydrodynamics, M.I.T., Cambridge, Massachusetts (October 1972).

[2] Fread, D.C., "Techniques for Implicit Dynamic Routing with Tributaries," Water Resources Research, 9, 4 (August 1973), 918-926.

[3] Gunaratnam, Daniel and Frank E. Perkins, "Numerical Solutions of Unsteady Flows in Open Channels," Hydrodynamics Laboratory T.R. No. 127, Department of Civil Engineering, M.I.T., Cambridge, Massachusetts (July 1970).

[4] O'Kane, G.P.G., "A prediction Model for the Pollution of Lee Estuary," Unpublished M. Eng. Sc. Thesis, National University of Ireland, Cork, Ireland (1968).

[5] Quinn, Frank, and Benjamin Wylie, "Transient Analysis of the Detroit River by the Implicit Method," Water Resources Research, 8, 6 (December 1972), 1461-1469.

[6] Stocker, J.J., Water Waves, New York, Interscience (1957).

[7] Wood, Eric F., "A Study of the Feasibility of Incorporating a Bridge section Routine into the M.I.T. Routing Mode1," Unpublished notes. Department of Civil Engineering, M.I.T., Cambridge, Massachusetts (December 1972). 